\title{
Excitation by Axon Terminal GABA Spillover in a Sound Localization Circuit
}

\author{
[CCatherine J.C. Weisz, ${ }^{1}$ Maria E. Rubio, ${ }^{1,2,3}{ }^{\oplus}$ Richard S. Givens, ${ }^{4}$ and ${ }^{\circledR}$ Karl Kandler ${ }^{1,2,3}$ \\ ${ }^{1}$ Department of Otolaryngology and ${ }^{2}$ Department of Neurobiology, University of Pittsburgh School of Medicine, Eye and Ear Institute, Pittsburgh, \\ Pennsylvania 15213, ${ }^{3}$ Center for the Neural Basis of Cognition, University of Pittsburgh, Pittsburgh, Pennsylvania 15213, and ${ }^{4}$ Department of Chemistry, \\ University of Kansas, Lawrence, Kansas 66045
}

Synapses from neurons of the medial nucleus of the trapezoid body (MNTB) onto neurons of the lateral superior olive (LSO) in the auditory brainstem are glycinergic in maturity, but also GABAergic and glutamatergic in development. The role for this neurotransmitter cotransmission is poorly understood. Here we use electrophysiological recordings in brainstem slices from P3-P21 mice to demonstrate that GABA release evoked from MNTB axons can spill over to neighboring MNTB axons and cause excitation by activating $\mathrm{GABA}_{\mathrm{A}} \mathrm{R}$. This spillover excitation generates patterns of staggered neurotransmitter release from different MNTB axons resulting in characteristic “doublet" postsynaptic currents in LSO neurons. Postembedding immunogold labeling and electron microscopy provide evidence that $\mathrm{GABA}_{\mathrm{A}}$ Rs are localized at MNTB axon terminals. Photolytic uncaging of $p$-hydroxyphenacyl (pHP) GABA demonstrates backpropagation of $\mathrm{GABA}_{\mathrm{A}} \mathrm{R}$-mediated depolarizations from MNTB axon terminals to the soma, some hundreds of microns away. These somatic depolarizations enhanced somatic excitability by increasing the probability of action potential generation. GABA spillover excitation between MNTB axon terminals may entrain neighboring MNTB neurons, which may play a role in the developmental refinement of the MNTB-LSO pathway. Axonal spillover excitation persisted beyond the second postnatal week, suggesting that this mechanism may play a role in sound localization, by providing new avenues of communication between MNTB neurons via their distal axonal projections.

Key words: caged neurotransmitter; GABA; LSO; MNTB; sound localization; spillover

Significance Statement

In this study, a new mechanism of neuronal communication between auditory synapses in the mammalian sound localization pathway is described. Evidence is provided that the inhibitory neurotransmitter GABA can spill over between axon terminals to cause excitation of nearby synapses to further stimulate neurotransmitter release. Excitatory GABA spillover between inhibitory axon terminals may have important implications for the development and refinement of this auditory circuit and may play a role in the ability to precisely localize sound sources.

\section{Introduction}

Principal neurons of the mammalian lateral superior olive (LSO) receive acoustic information from the two ears to compute inter-

Received March 24, 2015; revised Nov. 24, 2015; accepted Dec. 4, 2015.

Author contributions: C.J.C.W. and K.K. designed research; C.J.C.W. and M.E.R. performed research; R.S.G. contributed unpublished reagents/analytic tools; C.J.C.W. and M.E.R. analyzed data; C.J.C.W., M.E.R., R.S.G., and K.K. wrote the paper.

This work was supported by National Institute on Deafness and Other Communication Disorders Grant DC04199 to K.K. and Grant DC013048 to M.E.R., Kansas University Endowment Association Research Fund to R.S.G., T32 DC011499 to C.J.C.W., and F32 DC013207 to C.J.C.W. We thank Mahnoor Moin for analysis assistance and Hannah Roos for technical support.

The authors declare no competing financial interests.

Correspondence should be addressed to Dr. Karl Kandler, Department of Otolaryngology, University of Pittsburgh School of Medicine, Biomedical Science Tower 3, 3501 Fifth Avenue, Pittsburgh, PA 15261. E-mail: kkarl@pitt.edu.

C.J.C. Weisz's present address: Section on Neuronal Circuitry, National Institute on Deafness and Other Communication Disorders-National Institutes of Health, Bethesda, MD 20892.

DOI:10.1523/JNEUROSCI.1132-15.2016

Copyright $\odot 2016$ the authors $\quad 0270-6474 / 16 / 360911-15 \$ 15.00 / 0$ aural intensity differences used to localize sound sources in the azimuth (Boudreau and Tsuchitani, 1970; Caird and Klinke, 1983; Oertel, 1999; Tollin, 2003). In maturity, LSO neurons receive glutamatergic synapses from the ipsilateral cochlear nucleus and glycinergic synapses from the contralateral ear via the medial nucleus of the trapezoid body (MNTB) (Finlayson and Caspary, 1989; Sanes, 1993; Kandler and Friauf, 1995). During development, MNTB-LSO synapses are also glutamatergic (Gillespie et al., 2005) and GABAergic (Kotak et al., 1998; Korada and Schwartz, 1999; Kim and Kandler, 2003; Nabekura et al., 2004). Neurotransmitter cotransmission has been documented in numerous synapses (for review, see Hnasko and Edwards, 2012; Vaaga et al., 2014), but the role of multineurotransmitter release from developing MNTB neurons onto LSO neurons is poorly understood. Loss of glutamate cotransmission at MNTB-LSO synapses impairs the developmental refinement of MNTB-LSO connections (Noh et al., 2010). However, despite the fact that 
MNTB-LSO synapses are predominantly GABAergic before hearing onset (Kotak et al., 1998; Nabekura et al., 2004), the role for GABA release at this synapse is not well understood.

Early in development in the MNTB-LSO circuit, the chloride current mediated by $\mathrm{GABA}_{\mathrm{A}}$ or glycine receptors in postsynaptic LSO neurons is excitatory, generating action potentials (Kandler and Friauf, 1995; Ehrlich et al., 1999; Kullmann and Kandler, 2001) in addition to an increase in intracellular calcium (Kullmann et al., 2002). With development, the $\mathrm{GABA}_{\mathrm{A}} \mathrm{R}$-mediated component decreases, the glycine current increases to become dominant, and postsynaptic LSO responses become both larger and faster (Sanes, 1993; Kandler and Friauf, 1995; Kotak et al., 1998; Nabekura et al., 2004; Kim and Kandler, 2010). GABA $_{B} R$ on postsynaptic LSO neurons mediates synaptic depression (Kotak et al., 2001; Chang et al., 2003), whereas $\mathrm{GABA}_{\mathrm{B}} \mathrm{R}$ on presynaptic MNTB axons have been implicated in synaptic circuit development (Kotak et al., 2001; Grothe and Koch, 2011) and in adjusting the strength of MNTB-LSO synapses (Magnusson et al., 2008).

The excitatory action of "inhibitory" neurotransmitters at presynaptic axon terminals is receiving increased attention. Glycine and $\mathrm{GABA}_{\mathrm{A}}$ receptors on presynaptic terminals have been long hypothesized and demonstrated (Eccles et al., 1963; Turecek and Trussell, 2001; Ruiz et al., 2003; Pugh and Jahr, 2011). Presynaptic $\mathrm{GABA}_{\mathrm{A}} \mathrm{R}$ and glycine receptors can either have excitatory (Turecek and Trussell, 2002; Jang et al., 2006; Alle and Geiger, 2007; Stell et al., 2007) or inhibitory (Eccles et al., 1963; Zhang and Jackson, 1995; Glickfeld et al., 2009) effects on synaptic transmission. Recent work has demonstrated excitatory presynaptic activity of $\mathrm{GABA}_{\mathrm{A}} \mathrm{R}$ in other systems, including cerebellum where $\mathrm{GABA}_{\mathrm{A}} \mathrm{R}$ activation increases the somatic or axon initial segment excitability (Pugh and Jahr, 2011, 2013) or increases action potential conduction velocity (Dellal et al., 2012) or probability (Stell, 2011). At the calyx of Held synapse onto MNTB neurons, $\mathrm{GABA}_{\mathrm{A}}$ and glycine receptor activation increases neurotransmitter release (Turecek and Trussell, 2001, 2002). Here we demonstrate that GABA spillover between MNTB axon terminals in the LSO can excite MNTB axons by presynaptic $\mathrm{GABA}_{\mathrm{A}} \mathrm{R}$ activation, which causes excitation of axon terminals and neurotransmitter release. In addition, GABA-evoked depolarization of axon terminals in the LSO can propagate back to MNTB somata where it increases neuronal excitability. Excitatory GABA spillover between MNTB terminals may play a role in the developmental refinement of MNTB-LSO connections and, after hearing onset, may provide a novel mechanism to coordinate activity of similarly tuned MNTB neurons with overlapping LSO termination patterns.

\section{Materials and Methods}

Animals and slice preparation. Brain slices were prepared from C57BL/6J mice (Charles River) of either sex aged postnatal day 3 (P3)-P14 and $\mathrm{P} 20-\mathrm{P} 21$. The $300-350 \mu \mathrm{m}$ transverse brain slices containing both MNTB and LSO neurons were cut with a vibratome (Leica) in aCSF (in $\mathrm{mm}$ ) as follows: $124 \mathrm{NaCl}, 1.3 \mathrm{MgSO}_{4}, 5 \mathrm{KCl}, 1.25 \mathrm{KH}_{2} \mathrm{PO}_{4}, 10$ dextrose, $26 \mathrm{NaHCO}_{3}, 2 \mathrm{CaCl}_{2} ; 1 \mathrm{~mm}$ kynurenic acid was included during slice preparation, $\mathrm{pH}, 7.4$ when bubbled with $95 \% \mathrm{O}_{2} / 5 \% \mathrm{CO}_{2}$. Slices were stored at $32^{\circ} \mathrm{C}$ for $1 \mathrm{~h}$ in a custom interface chamber (for electrophysiological recordings) or submerged (for calcium indicator labeling), and then allowed to cool to room temperature. Slices were used within $4 \mathrm{~h}$ of preparation. During all experiments, slices were continuously bathed in recirculating aCSF bubbled with $95 \% \mathrm{O}_{2} / 5 \% \mathrm{CO}_{2}$ at room temperature.

Electrophysiological recordings. Recordings were performed using a MultiClamp 700B and DigiData 1440A controlled by Clampex 10.3 software (Molecular Devices). Recordings were sampled at $50 \mathrm{kHz}$ and fil- tered online at $10 \mathrm{kHz}$. Postsynaptic currents (PSCs) were recorded in LSO principal neurons identified by their large, bipolar morphology (Rietzel and Friauf, 1998), presence of an $\mathrm{I}_{\mathrm{h}}$ current, and absence of an A-type potassium current (Sterenborg et al., 2010). Internal solution for LSO voltage-clamp recordings contained the following (in $\mathrm{mm}$ ): $56 \mathrm{CsCl}$, $49 \mathrm{CsOH}, 54$ D-gluconic acid, $1 \mathrm{MgCl}_{2}, 1 \mathrm{CaCl}_{2}, 10 \mathrm{HEPES}, 11$ EGTA, 0.3-Na-GTP, 2 Mg-ATP, $3 \mathrm{Na}_{2}$-phosphocreatine, 5 QX-314. In some experiments, AlexaFluor-568 hydrazide $(10 \mu \mathrm{M})$ was included. $\mathrm{pH}$ was adjusted to 7.2 with $\mathrm{CsOH}$. The $\mathrm{Cl}^{-}$equilibrium potential was $\sim-20$ $\mathrm{mV}$. For "conditioning" experiments (see Fig. 6) (Magnusson et al., 2008), QX-314 was excluded from the solution. Internal solution for current-clamp LSO and MNTB recordings contained the following (in mM): $56 \mathrm{KCl}, 54 \mathrm{~K}$-gluconate, $1 \mathrm{MgCl}_{2}, 1 \mathrm{CaCl}_{2}, 10 \mathrm{HEPES}, 11$ EGTA, 0.3 Na-GTP, $2 \mathrm{Mg}$-ATP, $5 \mathrm{Na}_{2}$-phosphocreatine. $\mathrm{pH}$ was adjusted to 7.2 with $\mathrm{KOH}$. Recording pipettes were pulled from $1.5 \mathrm{~mm}$ outer diameter borosilicate glass (Sutter Instruments) to tip resistances of 3-6 $\mathrm{M} \Omega$. Series resistances were corrected $60 \%-80 \%$. Cells were voltage-clamped at -60 $\mathrm{mV}$ unless stated otherwise. Membrane voltages were not adjusted for a measured liquid junction potential of $-5 \mathrm{mV}$ (Cs gluconate solution) or $-6.5 \mathrm{mV}$ (K gluconate solution) unless noted. MNTB axons were electrically stimulated to evoke neurotransmitter release and generate PSCs in the LSO neuron by a glass pipette (tip resistance $\sim 1.5-3 \mathrm{M} \Omega$ ) filled with aCSF placed in the MNTB axon bundle, at the lateral edge of the MNTB. MNTB axons were stimulated at $0.1 \mathrm{~Hz}$, current amplitude 5-1000 $\mu$ A, by an Iso-Flex (AMPI). Drugs were bath applied by addition to the aCSF solution (Tocris Bioscience, Sigma).

In some experiments, the MNTB-LSO pathway was mechanically severed with a scalpel cut placed lateral to the boundaries of the MNTB, extending from the ventral surface of the brainstem dorsally to approximately the level of the ventral border of the trigeminal motor nucleus. Completeness of cut was evaluated by visually verifying the presence of a tissue-free gap between the slightly separated parts of the slice.

Two-photon imaging and GABA uncaging. Experiments were performed on a custom VIVO electrophysiology/2-photon rig (3I: Intelligent Imaging Innovations). Slices were visualized for electrophysiological recordings on a Zeiss Examiner D1 microscope with a $20 \times 1.0$ N/A objective. 2-Photon imaging of OGB-1 AM calcium dye and AlexaFluor-594 hydrazide-filled neurons was performed with a Chameleon Ultra infra-red laser (Coherent) tuned to $810 \mathrm{~nm}$ at $10 \%$ power ( $\sim 250 \mathrm{~mW}$, controlled by Pockels cell). Laser uncaging of RuBi-GABA was performed with a $488 \mathrm{~nm}$ solid state laser. Green and red emissions were detected by two GaAsP PMTs (Hamamatsu). Imaging and laser uncaging were controlled with SlideBook software version 5.0-5.5 (3I).

For GABA uncaging experiments, slices were incubated for $1 \mathrm{~h}$ with 2.5 mM OGB-1 AM calcium indicator dye dissolved in $20 \%$ pluoronic in DMSO (Invitrogen). MNTB neurons with axons extending to the LSO were identified as follows: a recording pipette was placed near the MNTB, containing $100 \mu \mathrm{M}$ AlexaFluor-594 hydrazide added to the internal solution. A stimulating electrode was placed in the medial LSO, containing aCSF with $10 \mu \mathrm{m}$ AlexaFluor-594 hydrazide for localization of the stimulation site under 2-photon imaging. MNTB axon terminals in the LSO were electrically stimulated (as above), $500 \mu \mathrm{A}, 3 \times 100 \mathrm{~Hz}$ every $5 \mathrm{~s}$, and MNTB somata were simultaneously imaged ( $810 \mathrm{~nm} 2 \mathrm{P}$ excitation, 400 ms interframe intervals). MNTB neurons that responded to the axon terminal stimulation with retrograde action potentials were identified by fluorescence increase $(\delta \mathrm{F} / \mathrm{F})$ coinciding with the electrical stimulation, indicating that their axons project to the LSO. The recording pipette was then positioned at the cell of interest using 2-photon excitation, and the MNTB neuron was patched for whole-cell current-clamp recording under bright-field illumination. RuBi-GABA $(20-100 \mu \mathrm{M})$ (Tocris Bioscience) was bath applied and uncaged using the $488 \mathrm{~nm}$ laser (3I) at $40 \%-100 \%$ power (of $50 \mathrm{~mW}$ ), guided by $2 \mathrm{P}$ imaging of tracer-filled MNTB axons $(810 \mathrm{~nm})$. Photostimulation laser pulse duration was $100-$ $500 \mathrm{~ms}$ for single pulses, or $100 \mathrm{~ms}$ pulses at $5 \mathrm{~Hz}$ for trains. Total train duration was 8-26 s. In separate experiments, pHP-GABA (100-500 $\mu \mathrm{M})$ (Givens et al., 1997, 1998) was bath applied. MNTB neurons with axons projecting to the LSO were identified as above. Uncaging of pHPGABA was performed using illumination from a mercury lamp transmit- 
ted via a 50 - or $200-\mu \mathrm{m}$-diameter optical fiber, positioned using brightfield optics (Kim and Kandler, 2003; Kandler et al., 2013).

Electron microscopy. Postembedding immunogold labeling after freeze substitution was performed as previously described (Rubio and Wenthold, 1997). In brief, after a 10 min transcardial perfusion with $4 \%$ PFA and $0.5 \%$ glutaraldehyde in $0.1 \mathrm{~m}$ phosphate buffer, and $1 \mathrm{~h}$ postfixation at $4^{\circ} \mathrm{C}$, fixed brains were cut into $150 \mu \mathrm{m}$ slices containing the LSO from P12 mice on a VT1000S vibratome (Leica Microsystems). Ultrathin sections $(80 \mathrm{~nm}$ ) were cut using a UC7 ultramicrotome (Leica Microsystems). Following freeze substitution with Lowycril HM20 (Electron Microscopy Sciences), ultrathin sections were incubated with a mouse monoclonal primary antibody against the N-terminal domain of $\mathrm{GABA}_{\mathrm{A}} \mathrm{R} \beta 2 / 3$ subunit (clone $62-3 \mathrm{G} 1 / 05-474$, Millipore) at a dilution of 1:100. The secondary anti-mouse antibody with $5 \mathrm{~nm}$-conjugated gold particles (Ted Pella) was applied at a dilution of 1:30. Sections were imaged at $\times 50,000$ or $\times 10,000$ magnification on a JEOL 1400 transmission electron microscope (JEOL). In the images the Adobe Photoshop was used to darken the gold particles to enhance visibility against background.

Data analysis and software. Electrophysiological data were analyzed using Clampfit 10.4, and spontaneous (s) PSCs were analyzed with MiniAnalysis version 6.0.7 (Synaptosoft). To isolate the effect of drugs on MNTB inputs, only large amplitude PSCs were analyzed as an attempt to avoid sPSCs generated by cochlear nucleus inputs (Kim and Kandler, 2010) as follow: For P3-P6, PSCs > 25 pA were analyzed, and for P7-P14, PSCs $>50 \mathrm{pA}$ were analyzed in control conditions. To adjust for the reduced amplitude of sPSCs in the presence of GABA receptor antagonists, the minimum acceptable sPSC amplitude was reduced by the same proportion as observed for the reduction of evoked synaptic responses in the same cells. Drug-induced difference of sPSC rates were tested by ANOVA with a post hoc Scheffé test.

Analysis of "doublets" was performed blind to the experimental condition and animal age using randomized file order and a custom MATLAB program (R2012a; MathWorks). If a drug had no apparent effect on doublet occurrence, then in some cases a second drug was added. If the second drug had an effect, then these cells were excluded from the washout population. Statistical tests included ANOVA with post hoc Scheffé, one-sample, and two-sample Student's $t$ tests, indicated in the text. Paired-pulse ratio (PPR) data plotted in Figure $2 G$ were fit to a Hill function with a zero intercept; then the predicted PPR value for a 3 ms interstimulus interval (ISI) was determined from the fitted curve. A range of predicted "PPR" values for $3 \mathrm{~ms}$ was calculated by translating the actual $5 \mathrm{~ms}$ PPR ratios to the predicted $3 \mathrm{~ms}$ PPR and applying the same $\mathrm{SD}$. The values for the predicted $3 \mathrm{~ms}$ PPR were then compared with the actual amplitude ratios measured from the second and first component of doublets using a paired $t$ test with Welch correction for unequal variances. For stimulus train data, the proportion of doublets was calculated from 3 to 24 trains of 20 pulses each. Statistical increase of doublets during a train was tested using linear regression analysis. The magnitude of the change in doublets during stimulus trains was calculated from the percentage difference between the first three stimuli, averaged, and the last three stimuli, averaged (Student's $t$ test). The number of PSCs during fast $(100-300 \mathrm{~Hz})$ trains was determined by eye (per 10 stimulations); then the difference in PSCs per 10 stimulations was compared across age groups by ANOVA with post hoc Scheffé. The interval from the onset of the first evoked PSC to the onset of the subsequent PSC (inter-PSC interval) was measured in pClamp and compared across age groups by ANOVA with post hoc Tukey's test. PPRs in control and drug conditions were compared using paired $t$ tests at each ISI. The "excitability index" to measure action potential threshold changes in response to GABA uncaging was calculated according to Pugh and Jahr (2013). Statistical analysis was performed with Origin 9.1 (Origin Laboratory). 2-Photon imaging data were collected and analyzed using SlideBook version 5.5 (3I). For fiber optic uncaging experiments, bright-field images were collected using a USB analog to digital converter (kworld) and CyberLink PowerDirector version 7 software. In the text, all data are presented as mean \pm SD.

\section{Results}

Whole-cell voltage-clamp recordings were performed from LSO primary neurons in brain slices from P3 to P21 mice. Electrical stimulation of MNTB axons evoked PSCs in LSO neurons. At low stimulation intensity, the evoked PSCs were monophasic, with amplitudes and kinetics consistent with previously published work (Sanes, 1993; Kotak et al., 1998; Kim and Kandler, 2003, 2010). However, in more than half of the cells (58 of 94), an unusual pattern of PSCs was observed at intermediate stimulus intensities. These unusual PSCs consisted of two or more components following a single stimulus. Further, the pattern of the two components was remarkably consistent with repeated stimulation $(0.1 \mathrm{~Hz}$ ) (Fig. $1 A$ ). We term this PSC pattern phenomenon "doublets." In a doublet PSC, the first component could occur without the second, but the second component was rarely observed without the first. The relative amplitude of the two doublet components was consistent for a given cell but variable between cells (Fig. 1A).

Doublets were recorded in slices from mice at all ages tested from P3 to P21 (Fig. 1B). The difference in the onset latencies between the first component and the second component was on average $\sim 3 \mathrm{~ms}$. Latency differences decreased slightly with age, but differences were not significant, except between the oldest and youngest animal groups (Fig. 1C). Doublets were further characterized in P3-P14 mice because the high rate of spontaneous synaptic activity in P20-P21 mice made unambiguous designation of doublets more difficult.

The amplitudes of each component of doublets were measured at membrane holding potentials from $-60 \mathrm{mV}$ to $40 \mathrm{mV}$ (Fig. 1D,E). Both doublet components reversed near the calculated chloride reversal potential $(-20 \mathrm{mV})$, suggesting that both components are mediated by $\mathrm{GABA}_{\mathrm{A}}$ and/or glycine receptors, consistent with GABA/glycinergic synaptic inputs from MNTB axons $(n=6)$. The proportion of doublets was unaffected by increasing the slice temperature to physiological temperature $\left(33^{\circ} \mathrm{C}-37^{\circ} \mathrm{C}\right)$ (proportion of doublets at room temperature: $0.70 \pm 0.26,70-120$ traces; $33-37^{\circ} \mathrm{C}: 0.77 \pm 0.24,60-130$ traces; return to room temperature: $0.76 \pm 0.31,40-240$ traces, $n=7$ cells, $p=0.85$ ).

The amplitudes and rise times of the first and second doublet components were measured in cells in which the two components had distinct peaks. Across all cells, the amplitude of the first component was larger than that of the second component (first component $531.7 \pm 964.5 \mathrm{pA}$, second component $170.4 \pm 197.7$ $\mathrm{pA}, p=0.036, n=25)$. When separated by age, however, the amplitudes only differed statistically for the P6-P8 age group (first component $432.5 \pm 391.3 \mathrm{pA}$, second component $88.6 \pm$ $48.3 \mathrm{pA}, n=8, p=0.044$; Fig. $1 F, G)$. Across all cells, the rise time of the first component was longer than that of the second component (first component $2.22 \pm 0.78 \mathrm{~ms}$, second component $1.52 \pm 0.68 \mathrm{~ms}, n=25 ; p<0.0001)$, although this difference did not reach statistical significance in the P12-P14 group (first component $1.57 \pm 0.38 \mathrm{~ms}$, second component $1.16 \pm 0.42 \mathrm{~ms}, n=$ $5, p=0.087$; Fig. $1 H, I)$. Shorter rise times for the second component may reflect differences in dendritic filtering due to different dendritic locations, or a membrane shunting due to open neurotransmitter receptor channels caused by the first component. As expected (Kim and Kandler, 2010), the rise times of the first component accelerated with increasing animal age (P3-P5 compared with both P9-P11 and P12-P14, $p<0.0001, n=25$; Fig. $1 H, I)$. To test for possible different locations of the synapses mediating the first and second component, we calculated the 


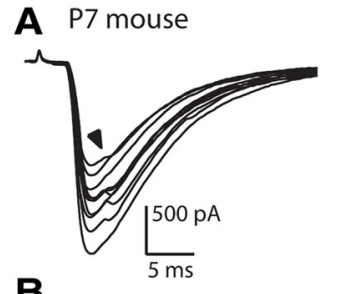

B
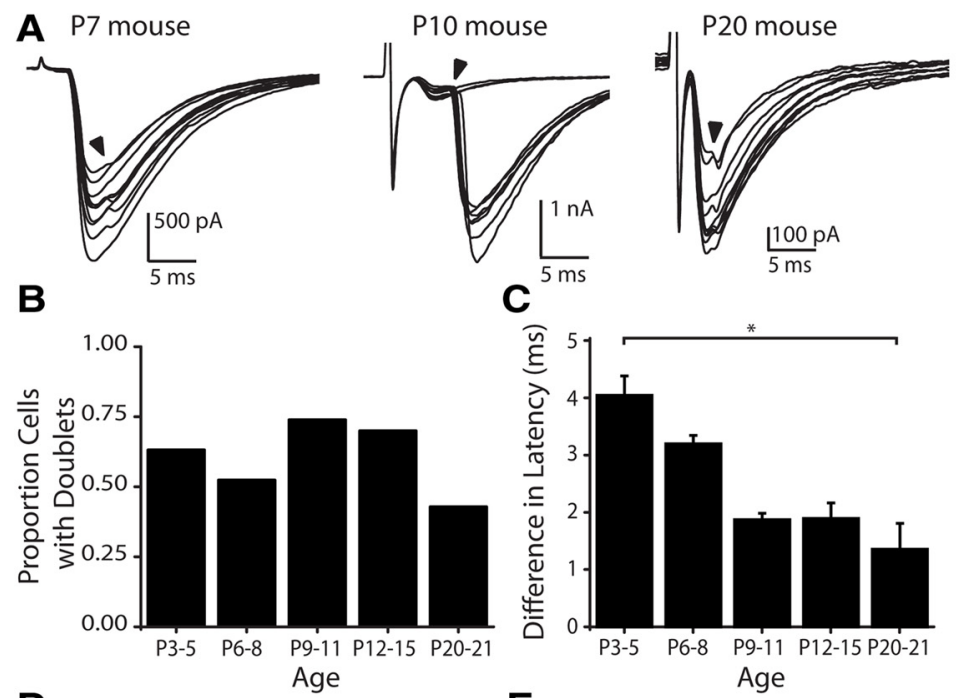

D

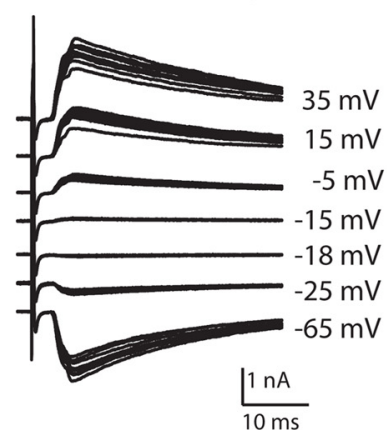

$\mathbf{F}$
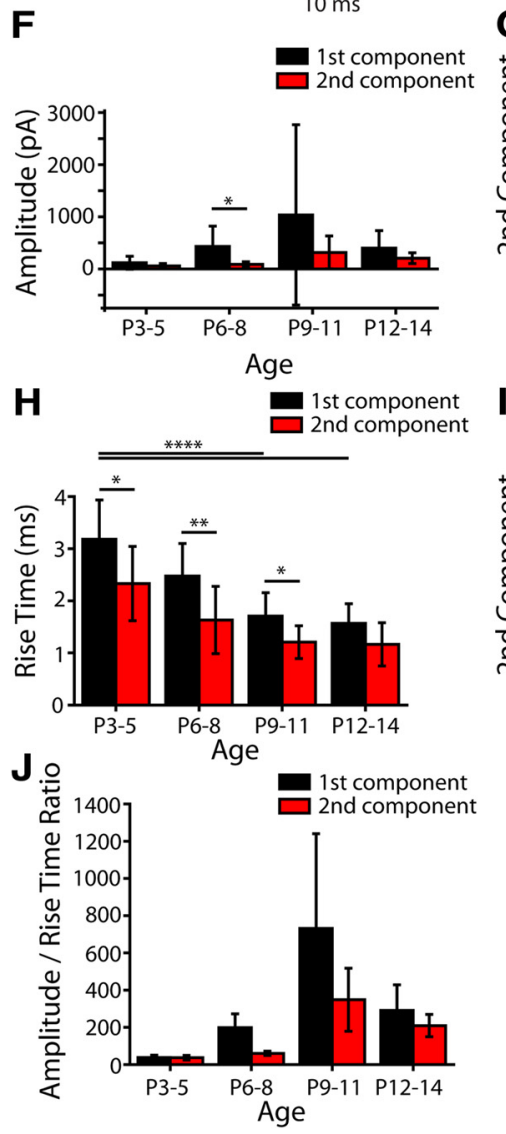

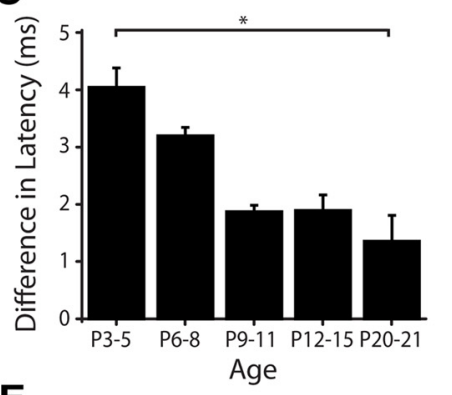

$\mathbf{E}$
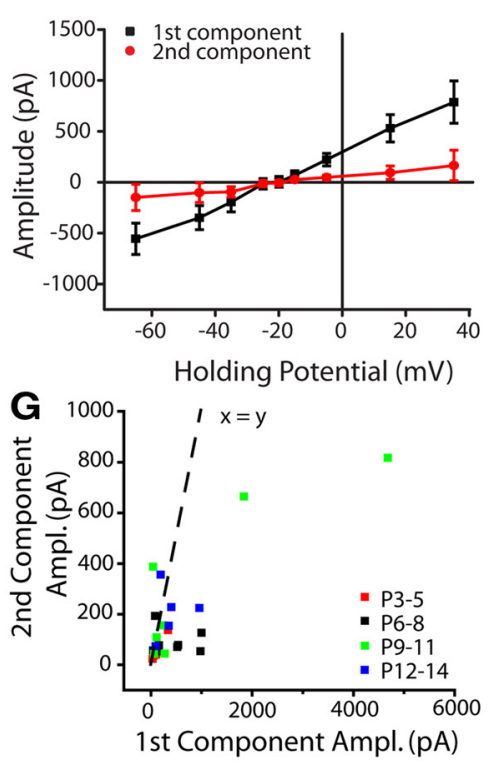

I

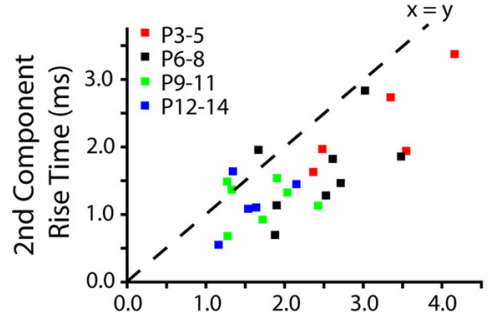

K 1st Component Rise Time (ms)

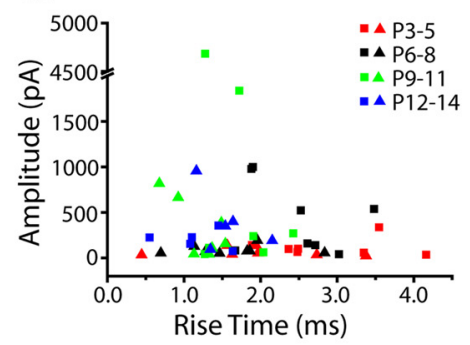

Figure 1. Characterization of "doublet PSCs" at developing MNTB-LSO synapses. $A$, Example "doublet" PSCs recorded in LSO neurons in response to electrical stimulation of MNTB axons. Ten overlaid sequential traces evoked at $0.1 \mathrm{~Hz}$. Arrowhead indicates onset of second component of doublet. $\boldsymbol{B}$, Proportion of neurons in which doublets were observed, grouped by postnatal age (left to right, $n=19,42,23,10,7) . C$, Average latency from onset of the first component of doublets to onset of the second component, ratio between the amplitude and rise time of the two doublet components (Fig. $1 J, K)$. No differences were detected between the amplitude/rise time ratio for the first and second doublet components overall (first component $333.8 \pm 743.8$ $\mathrm{pA} / \mathrm{ms}$, second component $164.4 \pm 267.4$ $\mathrm{pA} / \mathrm{ms}, n=25 ; p=0.111)$ or at any age group (Fig. $1 H, I$ ), suggesting that synapses mediating the two components are not localized to separate somatodendritic compartments.

Each component of a doublet is evoked from distinct MNTB neurons

To test whether the two components of a doublet were caused by the same or by different MNTB axons, we performed four experiments. First, recordings were performed from LSO neurons while MNTB axons were stimulated with trains of electrical pulses from 100 to $300 \mathrm{~Hz}$. At all ages tested, MNTB neurons were able to reliably release neurotransmitter with $100 \mathrm{~Hz}$ stimulation (inter-PSC interval average $11.2 \pm 1.5 \mathrm{~ms}, n=24$ cells; Fig. $2 B)$. With the exception of the P12-P14 age group, the rate of PSCs decreased with faster stimulation rates, yielding a longer average inter-PSC interval $(200 \mathrm{~Hz}$ pooled average $20.7 \pm 15.12$ ms latency, $n=22$ cells; $p>0.05$ compared with $100 \mathrm{~Hz} ; 300$ $\mathrm{Hz}$ pooled average $23.2 \pm 15.3 \mathrm{~ms}$ latency, $n=16$ cells, $p>0.05$ compared with 100 $\mathrm{Hz}$ Fig. $2 B$ ). The decreased rate of release at higher stimulation frequencies was evident in the decreasing number of PSCs elicited by 10 sequential stimuli delivered at increasing rates (Fig. 2C). The shortest PSC intervals observed at any stimulation

\footnotetext{
$\leftarrow$

grouped by postnatal age (left to right, $n=12,22,17,7,3$ ). $\boldsymbol{D}$, Example doublet traces recorded at the membrane holding voltages indicated (after liquid junction potential correction). Ten sequential overlaid traces of evoked currents generated at $0.1 \mathrm{~Hz}$. $\boldsymbol{E}$, The first and second components of the doublet PSC have the same reversal potential of $\sim-20 \mathrm{mV}$, corresponding to the $\mathrm{Cl}^{-}$reversal potential (average of 6 neurons, after liquid junction potential correction). $\boldsymbol{F}$, Average amplitude of first and second components of doublets grouped by postnatal age (left to right by age group, $n=5,8,7,5)$. G, Relationship between the amplitudes of the second doublet component and first doublet component for each cell. $\boldsymbol{H}$, Comparison of the rise times of the first and second components of doublets, grouped by postnatal age (left to right by age group, $n=5,8,7,5)$. $I$, Relationship between rise times of the second component and first component for each cell. J, Amplitude/rise time ratio plotted for the first and second doublet components, grouped by postnatal age $(n=5,8,7,5)$. $\boldsymbol{K}$. Amplitude by rise time for each cell, for both the first component (squares) and the second component (triangles). $\boldsymbol{F}-\boldsymbol{K}$, Only cells in which the second component started after the peak of the first component were included. Error bars indicate SEM. ${ }^{*} p<0.05,{ }^{* *} p<0.01$, $* * * 0<0.0001$.
} 
A $100 \mathrm{~Hz} \mathrm{stim}$

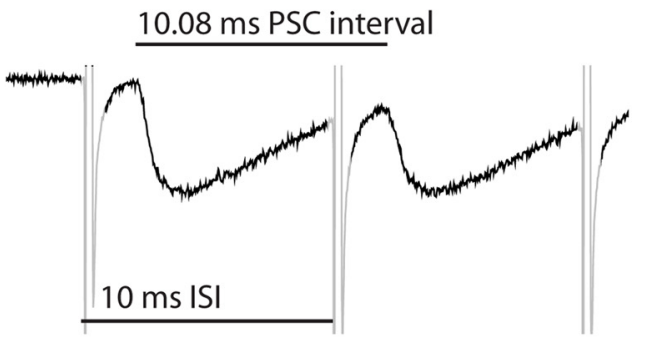

B

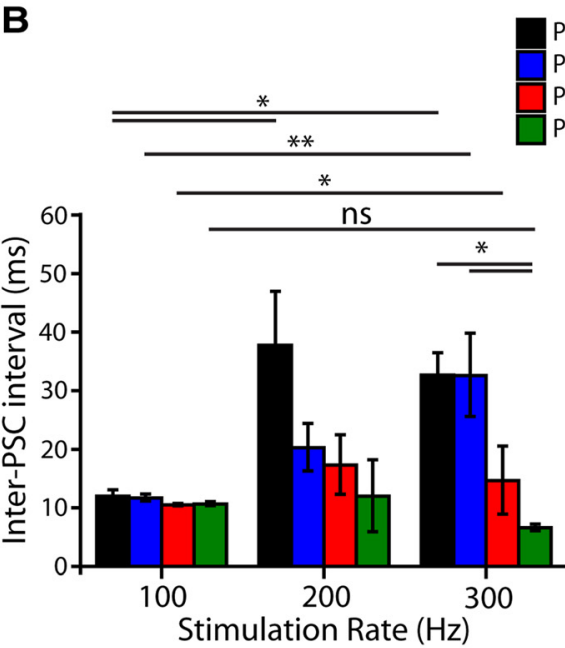

$300 \mathrm{~Hz}$ stim

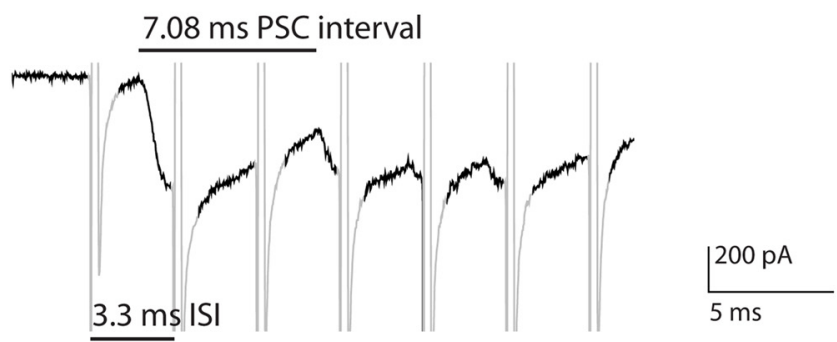

P9-11

P12-14
C

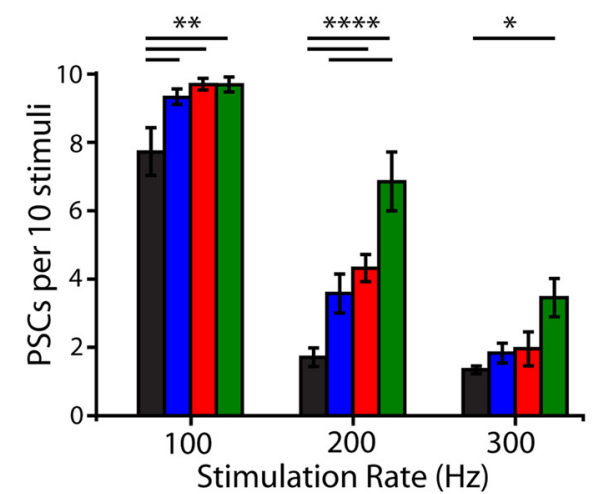

P $3-5$

P6-8

P9-11

P 12-14
D

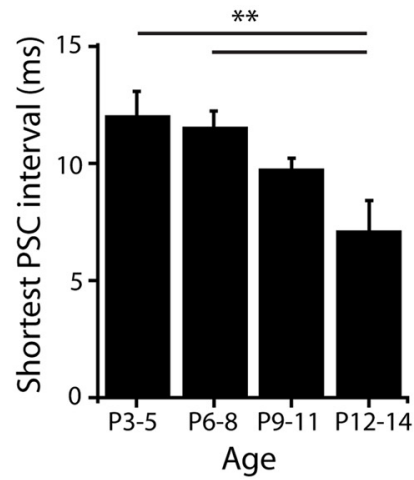

E

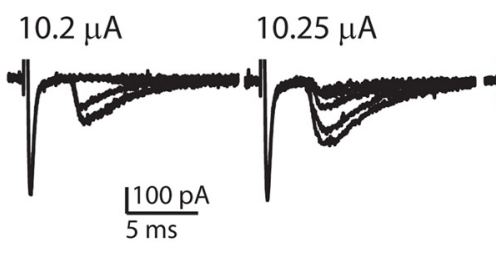

$15 \mu \mathrm{A}$

$35 \mu \mathrm{A}$

$50 \mu \mathrm{A}$

G
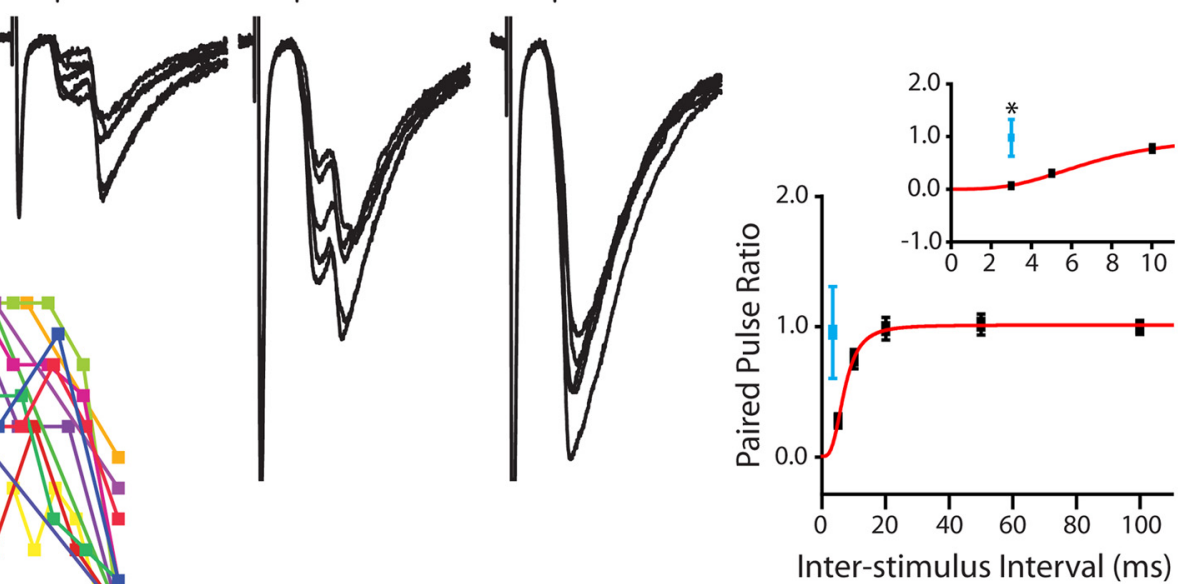

F

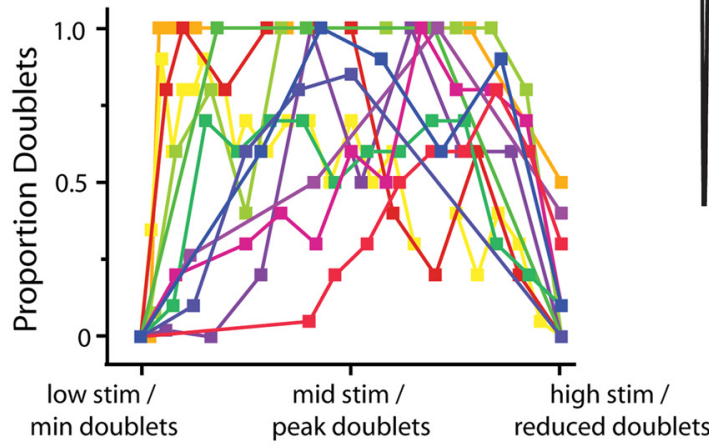

Normalized stimulus amplitude

Figure 2. The two components of a doublet PSC are generated by different populations of MNTB neurons. $A$, Left, PSCs elicited by electrical stimulation of MNTB axons at $100 \mathrm{~Hz}$. ISI (bottom) and resulting inter-PSC interval (top) indicated. Gray represents stimulus artifact. Right, Same neuron, PSCs elicited by $300 \mathrm{~Hz}$ stimulation. $\boldsymbol{B}$, Average inter-PSC interval for the first two PSCs evoked by stimulation trains at $100-300 \mathrm{~Hz}$, grouped by postnatal age. $C$, Average number of PSCs evoked by 10 pulses of stimulation at different frequencies, grouped by postnatal age. $\boldsymbol{D}$, Average shortest inter-PSC interval at any stimulation rate between the first and second PSC. B-D, P3-P5, $n=4$ or 5; P6-P8, $n=5-8 ; P 9-P 11, n=4-6 ; P 12-P 14, n=3-5$. E, Example traces showing the electrical stimulation intensity dependence of doublet PSCS, 5 traces overlaid perstimulation intensity. Stimulation current amplitudes indicated above traces. $\boldsymbol{F}$, Relationship between the proportion of doublets (of 10 sequential MNTB shocks at $0.1 \mathrm{~Hz}$ ) and stimulus intensity. Each line indicates a single cell, 12 cells overlaid. "Low stim/min doublets" indicates the stimulus intensity with zero doublets, just below the intensity at which doublets first occurred. "Mid stim/peak doublets" indicates the stimulus intensity at which the highest proportion of doublets were observed. "High stim/reduced doublets" indicates the stimulus intensity at which doublets were reduced to their minimum, following the peak. Stimulus amplitude was normalized to the range of low and high intensity for each cell. Actual stimulus amplitudes for plotted cells varied ("low stim" range 5-50 $\mu \mathrm{A}$, average $18.2 \pm 14.7 \mu \mathrm{A}$; "high stim" range 25-500 $\mu \mathrm{A}$, average $101.3 \pm 127.9 \mu \mathrm{A}, n=12$ cells). G, PPRs plotted by ISI (black, $n=10$ cells). Data were fit with a Hill function (red line) with $V_{\max }=1.007, k=6.917$, $n=3.012$. Ratio between the second and the first component of "doublet" PSCs plotted in blue ( $n=25$ cells). Inset, Zoom of $x$-axis. Predicted PPR for a $3 \mathrm{~ms} I S \mid$ included. Errors bars taken from the $5 \mathrm{~ms}$ data point. Asterisk indicates significant difference between actual doublet ratio and predicted $3 \mathrm{~ms}$ PPR. $A-G$, Error bars indicate SEM. ns, Not significant. ${ }^{*} p<0.05$, ${ }^{* *} p<0.01$, ${ }^{* * *} p<0.0001$. 
A

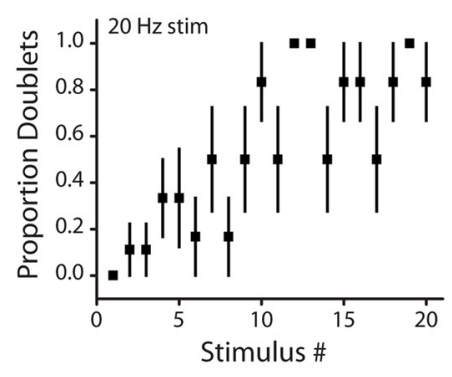

B

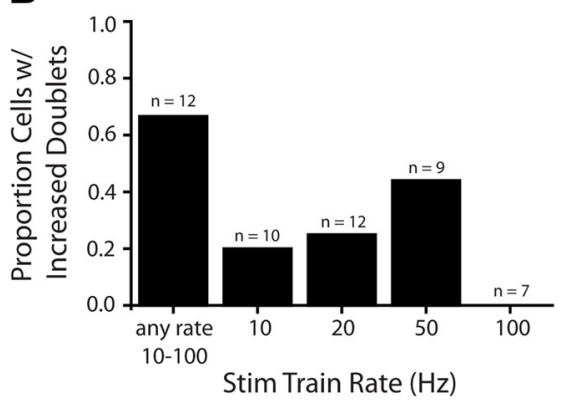

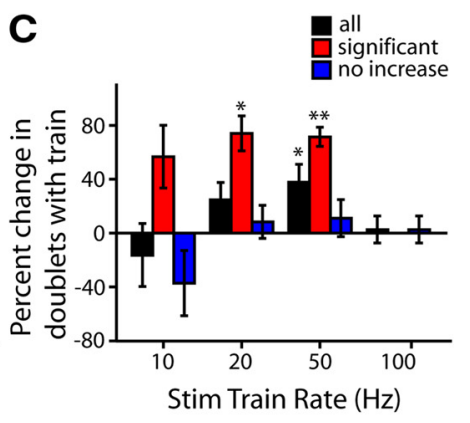

Figure 3. Rapid stimulation enhances the likelihood of eliciting doublet PSCS in LSO neurons. $A$, Proportion of doublets in evoked PSCS in a representative LSO neuron during a train of $20 \mathrm{~Hz}$ (average of 6-9 trains per data point). B, Proportion of cells in which proportion of doublets increased during the course of a stimulus train. $\boldsymbol{C}$, Histogram of the percentage change in doublets during train stimulation measured from the average of the first three pulses and the last three pulses in a 20 pulse train. Black represents pooled data from all cells. Red represents pooled data from subset of cells exhibiting an increase in doublets during trains. Blue represents pooled data from subset of cells exhibiting no increase in doublets during trains. $10 \mathrm{~Hz}: n=9,2,7 ; 20 \mathrm{~Hz}: n=12,3,9 ; 50$ $\mathrm{Hz}: n=9,4,5 ; 100 \mathrm{~Hz}: n=7,0,7$. Asterisks indicate data significantly different from zero. ${ }^{*} p<0.05,{ }^{* *} p<0.01$ (one-sample Student's $t$ test). A-C, Error bars indicate SEM.

frequency decreased as a function of age (Fig. 2D; shortest interPSC interval: $4.8 \mathrm{~ms}$ at P13). Importantly, the shortest possible inter-PSC interval was always longer than the $3 \mathrm{~ms}$ interval that occurred between the two components in a doublet, arguing against the possibility that the two components of a doublet are due to neurotransmitter release from the same MNTB axon(s).

Second, we determined the occurrence of doublets as a function of stimulus strengths. Doublets did not occur at minimal stimulation intensities at which $<50 \%$ of trials elicited a PSC. With increasing stimulation intensity, the proportion of doublets observed in 10 successive electrical stimulations at $0.1 \mathrm{~Hz}$ increased, suggesting that an increased number of activated axons generating additional neurotransmitter release promotes doublets. The average stimulation intensity that elicited the maximum proportion of doublets was $103.3 \pm 192.5 \mu \mathrm{A}(n=23)$; and on average, the doublet occurrence decreased at stimulation intensities $>220 \pm 268 \mu \mathrm{A}$ (range $40-1000 \mu \mathrm{A}$ ), with a clear loss of the second, but not the first, component $(n=26$; Fig. $2 E$; subset of 12 neurons with fine-grained stimulus increments plotted in Fig. $2 F$ ). This supports the hypothesis that the two components of doublets were evoked by neurotransmitter release from different MNTB axons; the second component of a doublet is indirectly caused by the first component. However, at high stimulation intensities, the MNTB axons responsible for the second component will be stimulated directly and the neurotransmitter release underlying both the first and second component will occur synchronously, yielding a large monophasic PSC (Fig. 2E). For further experimentation, the stimulus intensity was lowered to an intermediate value.

Third, if both doublet components arise from the same axon population, then one would expect that they would exhibit paired-pulse depression. To test this hypothesis, we compared the amplitude ratio of the second and first component in a doublet to the amplitude ratios of the first and second responses elicited by stimulus pairs (PPR). Because MNTB neurons do not release neurotransmitter at intervals as fast as $3 \mathrm{~ms}$ (Fig. $2 A-D$ ), we plotted PPRs for ISIs from 5 to $100 \mathrm{~ms}$. Using a curve fit to the data, we determined the predicted PPR value for an ISI of $3 \mathrm{~ms}$, corresponding to the $\sim 3$ ms doublet latency difference. The measured amplitude ratios of doublets were significantly different from the predicted $3 \mathrm{~ms}$ PPR (doublet ratio $0.957 \pm 1.765, n=$ 25; predicted PPR $0.073 \pm 0.173$ [variance taken from $5 \mathrm{~ms}$ data point $], n=10 ; p=0.02$ by two sample Student's $t$ test with Welch correction for unequal variance; Fig. $2 G$ ). This further supports the hypothesis that the two components of doublets originate from different MNTB axons.

Finally, we tested whether doublets could be due to the firing of two consecutive spikes in the same MNTB terminal, the first spike being directly elicited by the electrical stimulation and the second spike being a reflected antidromic spike generated in the MNTB soma or initial axonal segment. Because this scenario requires an intact $\mathrm{MNTB}$ soma, we tested for the presence of doublets in slices in which the MNTB-LSO pathway was severed (3 slices). Cutting the MNTB-LSO pathway did not abolish doublets, which were observed in 3 of 5 LSO neurons, indicating that the second component is not due to a reflected somatic spike.

\section{Repeated stimulation of MNTB axons increases the rate of doublets}

Rapid electrical stimulation of MNTB axons increased the occurrence of doublets. Stimulus trains (20 pulses) were applied to MNTB axons at rates from 10 to $100 \mathrm{~Hz}(n=3-24$ trains per experiment, per stimulation rate). Stimulus trains increased doublets in $66 \%$ of cells as determined by linear regression analysis $(n=12$ experiments; Fig. $3 \mathrm{~A}, B)$. Stimulation at $50 \mathrm{~Hz}$ was most effective at increasing the proportion of doublets during a train (increase in 4 of 9 cells; $p<0.01$ for each cell, all 9 cells increase: $37.8 \pm 39.5 \%, n=9, p=0.02 ; 4$ cells with a significant increase: $71.4 \pm 14.1 \%, n=4, p=0.002$; Fig. $3 B, C)$. The $10 \mathrm{~Hz}$ and $20 \mathrm{~Hz}$ stimulations were less effective in increasing doublet occurrence ( $10 \mathrm{~Hz}$ : increase in 2 of 10 cells, $p<0.01$, all 10 cells: $16.4 \pm 70.3 \%$ decrease, $n=9 ; 2$ cells with a significant increase: $56.7 \pm 33.0 \%$ increase, $n=2 ; 20 \mathrm{~Hz}$ : 3 of 12 cells, $p<0.05$, all 12 cells average increase $24.7 \pm 44.3 \%$, cells with significant increase: $73.9 \pm$ $22.5 \%, n=3, p=0.03$; Fig. $3 B, C)$. Stimulation at $100 \mathrm{~Hz}$ never increased doublets $(n=7$, average increase $2.6 \pm 26.6 \%$; Fig. $3 B, C)$.

Neurotransmitter receptors implicated in doublet generation Glycine, GABA, and glutamate, the three neurotransmitters released from developing MNTB-LSO connections, were each tested for their role in doublet generation. Receptor antagonists for these neurotransmitters were applied in experiments with a high initial proportion of doublets. When receptor antagonists reduced doublets, they did so by eliminating the second, not the first, component of the postsynaptic response (although the amplitude of both components of the doublet PSC could be equally reduced by postsynaptic receptor blockade). Impor- 

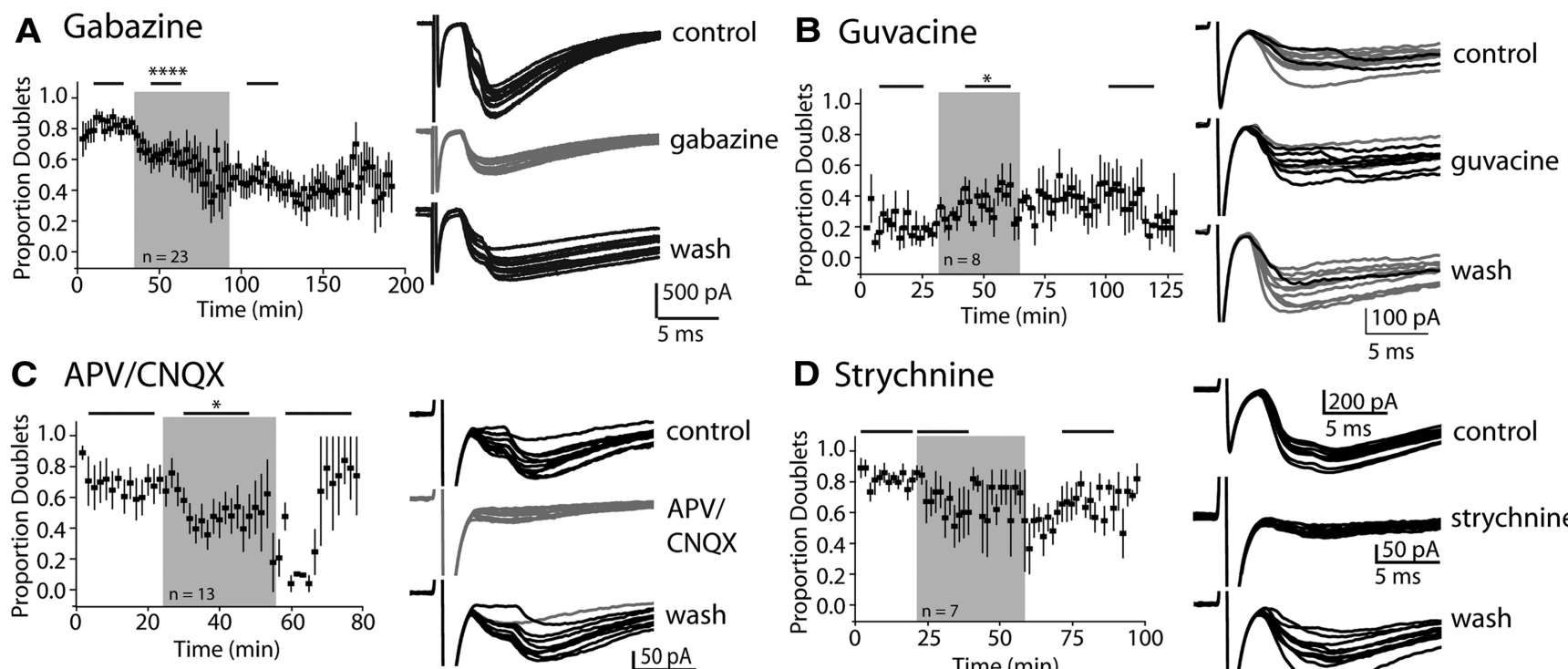

\section{Strychnine}

\section{E Saclofen}
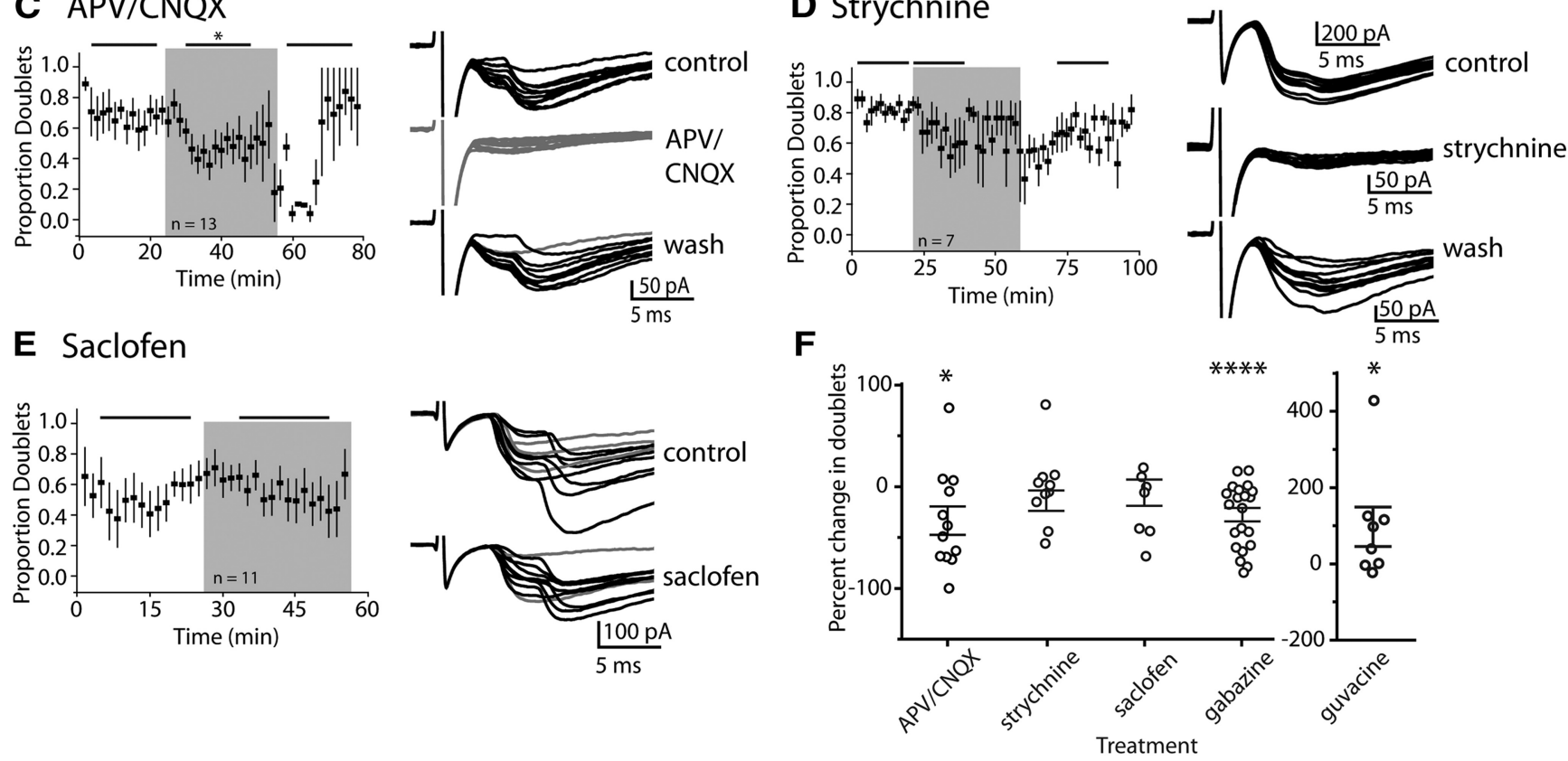

Figure 4. $G A B A_{A}$ and glutamate receptors are involved in the generation of doublet PSCS. $A-E$, Left, Proportion of evoked PSCs containing doublets. Each point represents the mean of $4-23$ cells (gabazine) or 3-13 cells (other drugs) for 10 sequential stimuli. Shaded box represents period of drug application. Data are aligned to the onset of drug. Lines above data indicate data range used for statistical tests, 12 time points per condition (window selected to include the maximal number of cells). Note the sudden baseline change and larger error bars in "wash" portion of $C$. Cells that did not respond to APV/CNQX were tested sequentially for other drugs and thus not included in wash. Therefore, wash portion only includes those cells in which APV/CNQX reduced doublets. * $p<$ 0.05 , compared with predrug conditions. ${ }^{* * *} p<0.0001$, compared with predrug conditions. Right, Example evoked PSC traces from a single cell before, during, and after application of drug indicated. Ten sequential traces overlaid; black represents doublet traces. Drugs that eliminated (gabazine, APV/CNQX) or enhanced (guvacine) the occurrence of doublets acted at the second component in a doublet but never the first component. $\boldsymbol{F}$, Percentage change in doublets in drug conditions compared with control, for the time points indicated by horizontal lines above the plots in $\boldsymbol{A}-\boldsymbol{E}$. Each dot indicates one cell. $\boldsymbol{A}-\boldsymbol{F}$, Error bars indicate SEM.

tantly, when doublet occurrence was reduced, the second component "blinked" in and out with each stimulating pulse in an all-or-nothing manner, instead of being gradually reduced in amplitude.

Application of the $\mathrm{GABA}_{\mathrm{A}}$ receptor antagonist gabazine (30 $\mu \mathrm{M})$ significantly reduced the occurrence of doublets (27.7 \pm $31.2 \%$ decrease, $p<0.0001, n=23$; Fig. $4 A, F)$. The ionotropic glutamate receptor blockers APV $(50 \mu \mathrm{M})$ and CNQX $(5 \mu \mathrm{M})$ also reduced doublets $(33.7 \pm 48.5 \%, p=0.018, n=13$; Fig. $4 C, F)$. In contrast, the glycine receptor antagonist strychnine $(100 \mathrm{nM})$ and the $\mathrm{GABA}_{\mathrm{B}}$ receptor antagonists saclofen $(30 \mu \mathrm{M})$ or CGP 54626 (100 nM, data not shown) did not reduce doublets (strychnine: $13.8 \pm 26.6 \%$ decrease, $p=0.11, n=7$; Fig. $4 D, F$; saclofen/CGP 54626: $5.8 \pm 40.9 \%$ decrease, $p=0.33, n=11$; Fig. $4 E, F)$. To better understand GABAergic signaling in the developing MNTB-LSO pathway, we focused the remainder of our experiments on the role of the $\mathrm{GABA}_{\mathrm{A}} \mathrm{Rs}$ in the generation of doublets.

To test whether an increase in GABA levels and $G_{A B A} R$ activation can increase the proportion of doublets in cells with a low doublet occurrence, GABA reuptake was blocked with guvacine $(30 \mu \mathrm{M})$. Guvacine significantly increased doublets (97.4 \pm
145.4\% increase, $p=0.049, n=8$; Fig. $4 B, F)$. The effect of guvacine, together with the increased occurrence of doublets with increased stimulus intensity or frequency (Figs. 2; 3), supports the hypothesis that GABA spillover excites MNTB axon terminals, which then generate the second, slightly delayed component in the doublet PSCs.

\section{Axonal location of $\mathrm{GABA}_{\mathrm{A}} \mathrm{R}$}

The above hypothesis predicts that MNTB axons in the LSO express presynaptic $\mathrm{GABA}_{\mathrm{A}} \mathrm{Rs}$. To explore this, we localized $\mathrm{GABA}_{\mathrm{A}} \mathrm{Rs}$ at putative MNTB axon terminals in the LSO using post-embedding immunogold labeling with an antibody against the $\beta 2 / 3 \mathrm{GABA}_{\mathrm{A}} \mathrm{R}$ subunits (de Blas et al., 1988). Putative MNTB presynaptic terminals were identified by their symmetric synaptic contacts typical of inhibitory synapses (Fig. 5A), which are distinct from the excitatory asymmetric synaptic contacts formed by presumed cochlear nucleus glutamatergic inputs (Fig. 5B). Consistent with previous studies in gerbils (Korada and Schwartz, 1999), $\mathrm{GABA}_{\mathrm{A}} \mathrm{R}$ labeling was found at inhibitory synaptic contacts on both cell bodies and dendrites in the LSO (Fig. $5 A, C$ ). Antibody labeling was not present at excitatory synaptic contacts 
(Fig. 5B). Within inhibitory synaptic terminals, $\mathrm{GABA}_{\mathrm{A}} \mathrm{R}$ labeling was found at the synaptic cleft as well as in axon terminal membranes opposite the synaptic contact (Fig. 5C,D). Although synaptic cleft immunolabeling could not be classified as presynaptic or postsynaptic because the antibody labels the extracellular $\mathrm{N}$ terminus of the receptor, the labeling at locations that are far from the synaptic cleft demonstrates nonsynaptic $\mathrm{GABA}_{\mathrm{A}} \mathrm{Rs}$ in presynaptic inhibitory terminals that may mediate interterminal GABA spillover. In support of this, axon terminal boutons, some of which possess nonsynaptic $\mathrm{GABA}_{\mathrm{A}} \mathrm{R}$ labeling, could be in close proximity to each other (Fig. $5 D$ ). Because the postembedding immunolabeling process affects visualization of membranes and makes classification of synapses more difficult, we examined different sections from the same tissue before immunolabeling. In these samples, identified inhibitory terminals were found adjacent to each other and not separated by glial membranes (Fig. 5E,F), supporting our hypothesis that GABA can diffuse between inhibitory axon terminals in the LSO.

\section{Doublets are not caused by dendritic GABA release}

In the LSO, GABA is released from presynaptic MNTB axons as well as postsynaptic LSO dendrites (Magnusson et al., 2008). To test whether GABA release from dendrites may underlie doublets, we performed "conditioning depolarization," stepping the holding potential of LSO neurons to 0,20 , and $40 \mathrm{mV}$ for 500 ms immediately before electrical stimulation, conditions that have been previously shown to evoke GABA release from LSO dendrites. We observed no effect of conditioning depolarization on doublet occurrence (proportion of doublets before conditioning pulse: $0.48 \pm 0.14$; proportion of doublets after conditioning pulse: $0.37 \pm 0.17, p=0.11$, paired $t$ test; $n=7$ cells, 20-180 repetitions per cell; Fig. 6A). Furthermore, depolarization conditioning of LSO neurons (Fig. 6B) did not increase spontaneous PSC frequency (control: $4.7 \pm 3.5 \mathrm{~Hz}$; conditioning: $4.1 \pm 3.1 \mathrm{~Hz}, p=0.29$, paired $t$ test; $n=12$ cells, 10-40 repetitions per cell; Fig. 6B). Finally, trains of postsynaptic action potentials elicited by brief current injections (500-2000 pA, 1 ms pulse duration, 100 $\mathrm{Hz}, 1 \mathrm{~s}$ train duration) had no effect on the rate of spontaneous postsynaptic potentials (control: $4.4 \pm 3.7 \mathrm{~Hz}$; during train: $4.7 \pm 5.3 \mathrm{~Hz}, p=0.78$, paired $t$ test;
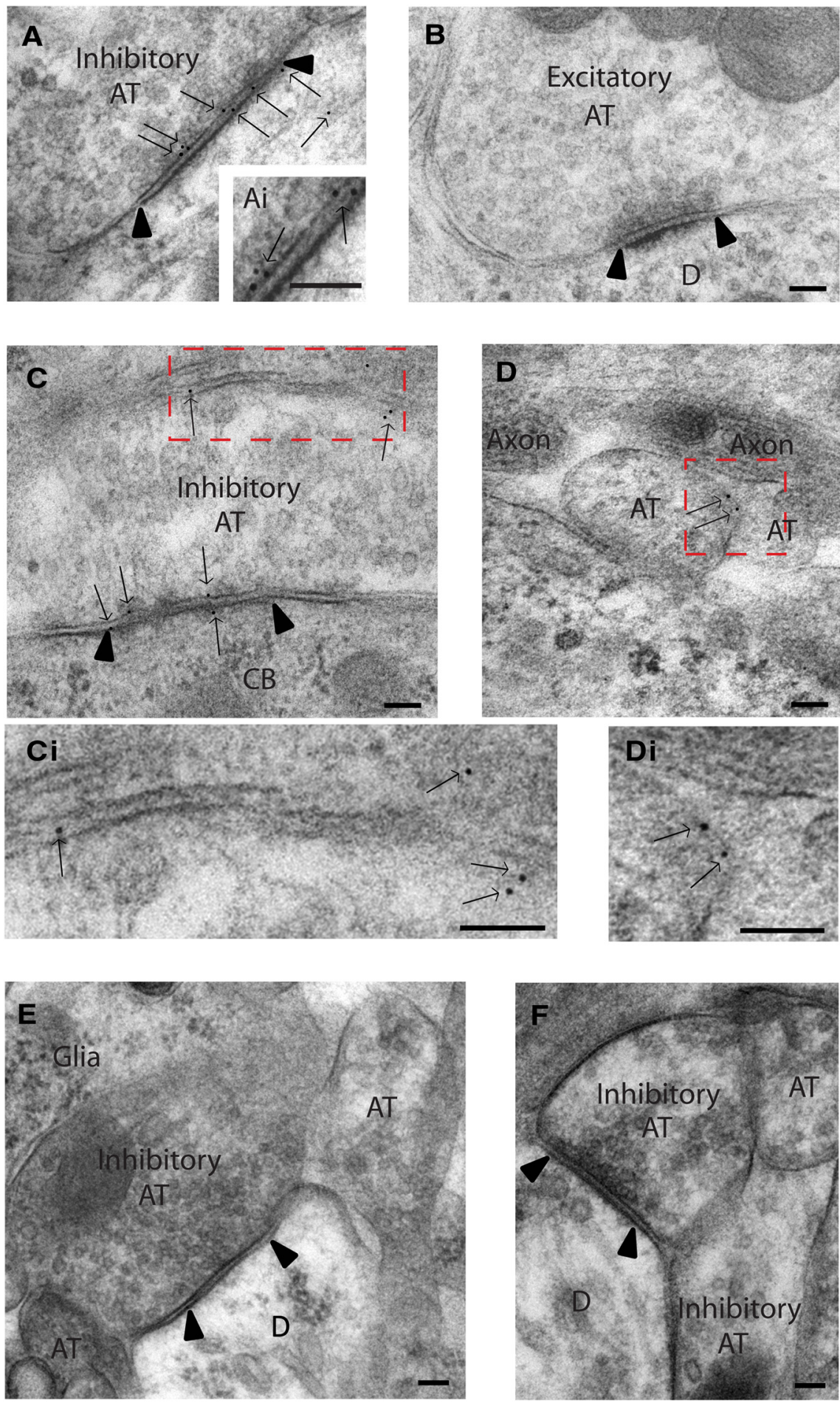

Figure 5. $G A B A_{A} R$ localization to inhibitory axon terminals in the $L S O$. $A$, Electron micrograph of a presumed MNTB axon terminal (AT) forming an inhibitory synaptic contact in the LSO (symmetric, extent indicated by arrowheads). Immunogold labeling of $\mathrm{GABA}_{\mathrm{A}} \mathrm{R}$ ( $5 \mathrm{~nm}$ gold particles, arrows). A postsynaptic intracellular gold particle is visible, possibly indicating a receptor being trafficked. $\boldsymbol{A i}$, Zoom of gold particle labeling in $\boldsymbol{A} . \boldsymbol{B}, G A B A_{A} R$ labeling is not observed at an excitatory synaptic contact (asymmetric, indicated by arrowheads) onto a dendrite (D). $\boldsymbol{C}$, Gold particles (arrows) label $G A B A_{A} R$ at an inhibitory synaptic contact (arrowheads) onto a cell body (CB), as well as at a second location opposite the synaptic contact (in red dashed box). Ci, Zoom of region indicated in C. $\boldsymbol{D}$, Gold particles (arrows) label $G A B A_{A} R$ (in red dashed box) at a nonsynaptic region of an AT, adjacent to another unidentified AT. Di, Zoom of region indicated in $\boldsymbol{D}$. $\boldsymbol{E}, \boldsymbol{F}$, Electron micrographs from sections that did not undergo immunolabeling. $E$, An inhibitory (presumed MNTB) synaptic contact (arrowheads) onto a dendrite (D) in the LSO, adjacent to two unidentified ATs. $\boldsymbol{F}$, An inhibitory AT synaptic contact (arrowheads), adjacent to an inhibitory AT, and a third unidentified AT. Scale bar, $100 \mathrm{~nm}$. 


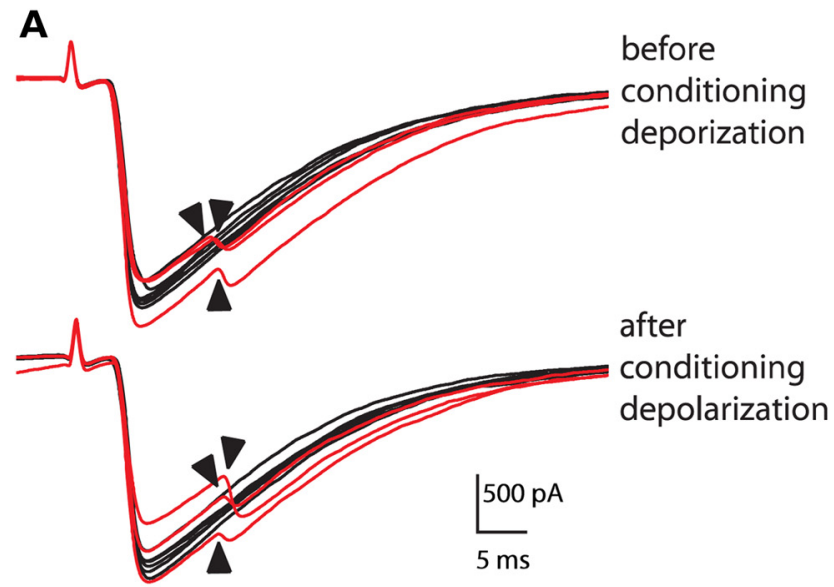

B

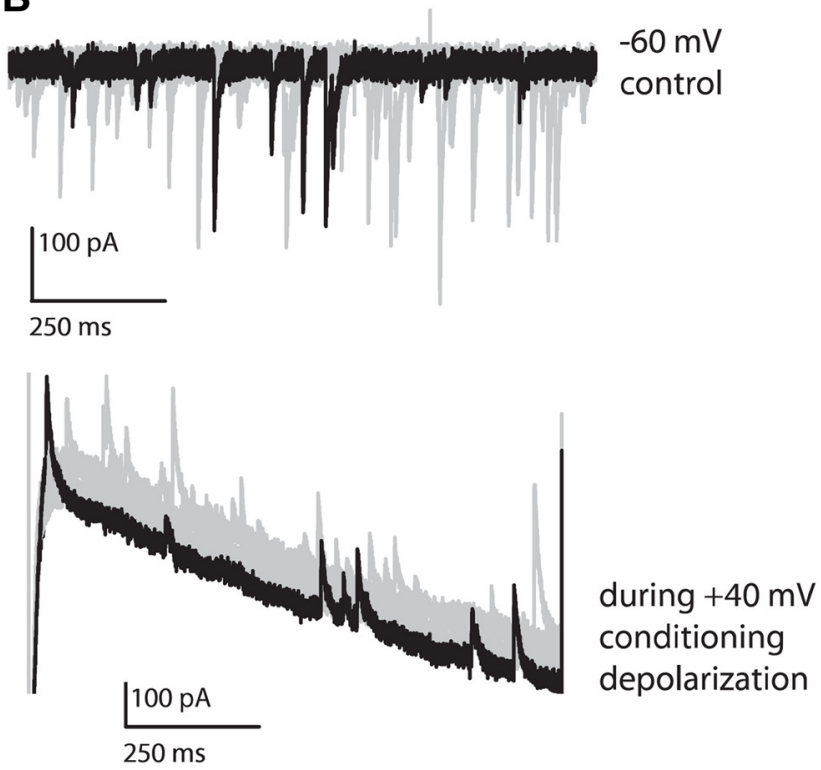

Figure 6. Doublet PSCs are not due to release of GABA from LSO dendrites. $A$, Top, Example of control PSCs with a proportion of doublets of 0.3 (average for this cell $0.35 \pm 0.33, n=6$ sets of 10 stimuli). Bottom, PS(s evoked with identical stimulation 20 ms following a "conditioning stimulus" depolarization to $0 \mathrm{mV}$ for $500 \mathrm{~ms}$. Proportion of doublets was 0.3 (average for this cell $0.33 \pm 0.21, n=6$ sets of 10 stimuli, $2-20$ ms following conditioning depolarization). Red represents doublet traces. Black represents monophasic traces. $\boldsymbol{B}$, Example traces showing spontaneous events in control conditions ( $-60 \mathrm{mV}$ ) and during "conditioning stimulation" (40 $\mathrm{mV}$ ). Ten overlaid traces; black represents single trace. Depolarization to $40 \mathrm{mV}$ did not increase PSCs.

$n=5-17$ trains for each cell, $n=5$ cells). These results indicate that LSO dendrites are not the source of GABA that acts at MNTB axonal terminals to evoke doublet PSCs. Instead, the most likely source of GABA causing doublets are the MNTB axons themselves.

\section{Presynaptic activity of GABA at MNTB axons}

Presynaptic, excitatory glycine or $\mathrm{GABA}_{\mathrm{A}} \mathrm{R}$ activity can increase neurotransmitter release by increasing the probability of release (Turecek and Trussell, 2001, 2002; Ruiz et al., 2003; Awatramani et al., 2005; Stell et al., 2007; Pugh and Jahr, 2011) or by generating presynaptic action potentials (Pugh and Jahr, 2013). To test whether $\mathrm{GABA}_{\mathrm{A}} \mathrm{R}$ on MNTB axon terminals change release probability, we performed paired-pulse experiments and measured changes in spontaneous neurotransmitter release in response to

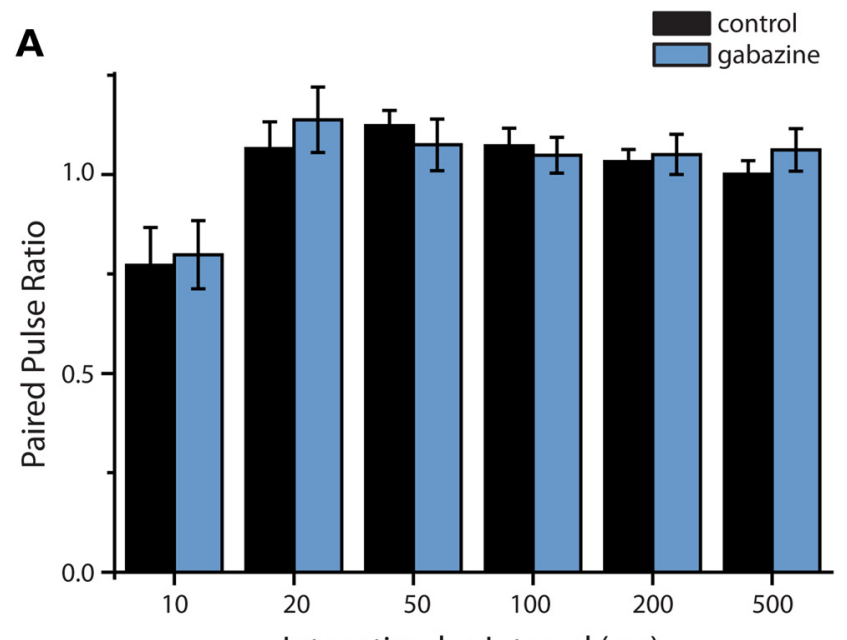

Inter-stimulus Interval (ms)

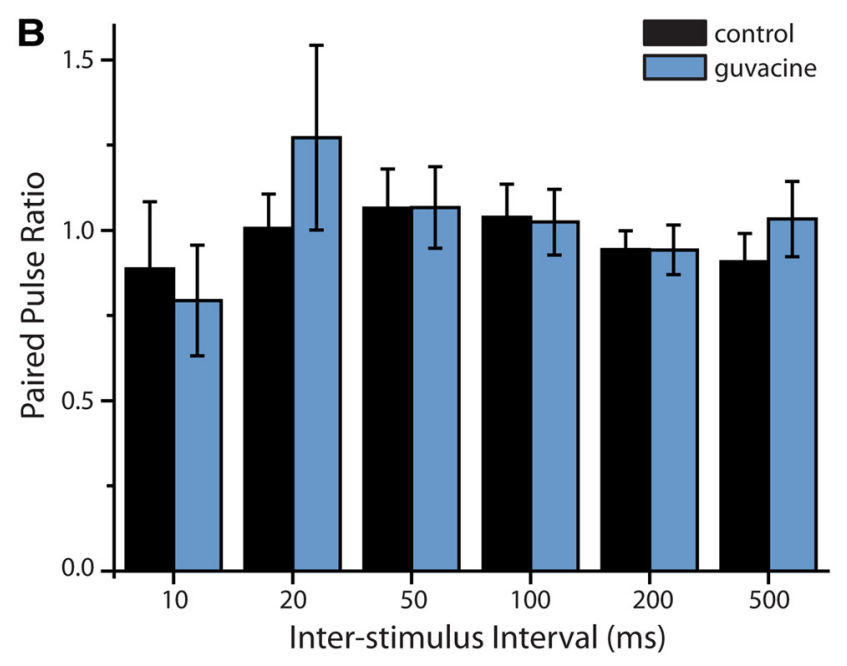

Figure 7. PPRs are unaffected by presynaptic $G A B A_{A}$ receptor activation. $A$, PPRs at varying ISIs in control (black) and in the presence of $30 \mu \mathrm{m}$ gabazine (blue) $(n=12-15$ cells per $|S| ; n=$ 12-50 traces per ISI per cell). $\boldsymbol{B}$, PPRs in control (black) and in the presence of $30 \mu \mathrm{m}$ guvacine (blue) ( $n=6$ or 7 cells per ISI; $n=12-40$ traces per ISI per cell). Data are mean \pm SEM.

pharmacological activation or blockade of $\mathrm{GABA}_{\mathrm{A}} \mathrm{R}$. PPRs (ISIs 10-500 ms), similar to previously published data (Kim and Kandler, 2010; Alamilla and Gillespie, 2013; Trattner et al., 2013), were not changed by gabazine $(30 \mu \mathrm{M})$ or guvacine $(30 \mu \mathrm{M})$ (gabazine vs control, $p>0.05$, paired $t$ tests, $n=12-15$ neurons; Fig. 7A; guvacine vs control, $p>0.05, n=7$ neurons; Fig. $7 B$ ). Because presynaptic $\mathrm{GABA}_{\mathrm{B}}$ Rs can decrease release probability from MNTB axons (Kotak et al., 2001), some of these release probability changes were tested in the presence of saclofen to eliminate any confounding effects of $\mathrm{GABA}_{B}$ R. However, even under the conditions of $\mathrm{GABA}_{\mathrm{B}} \mathrm{R}$ blockade, neither gabazine nor guvacine altered PPRs (gabazine vs control: $p>0.05$, paired $t$ tests, $n=5-7$ neurons per ISI; guvacine vs control: $p>0.05, n=$ 4 neurons per ISI). Gabazine and guvacine also did not change the variability of the PPR, which could have indicated a change in release probability (control vs gabazine: $p=0.55$ by ANOVA, ISIs pooled, $n=15$ cells, control vs guvacine $p=0.4089$ by ANOVA, ISIs pooled, $n=7$ cells). In addition, gabazine and guvacine did not change the spontaneous PSC rates in LSO neurons (gabazine: control: $1.74 \pm 1.36 \mathrm{~Hz}$, + gabazine: $1.91 \pm 1.41 \mathrm{~Hz}, n=7$ cells, $p=0.72$; guvacine: control: $0.93 \pm 1.30 \mathrm{~Hz},+$ guvacine: $1.74 \pm$ 
A
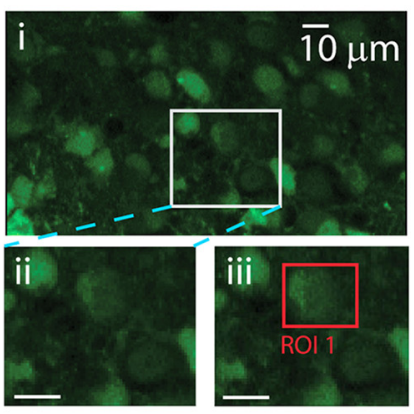

C

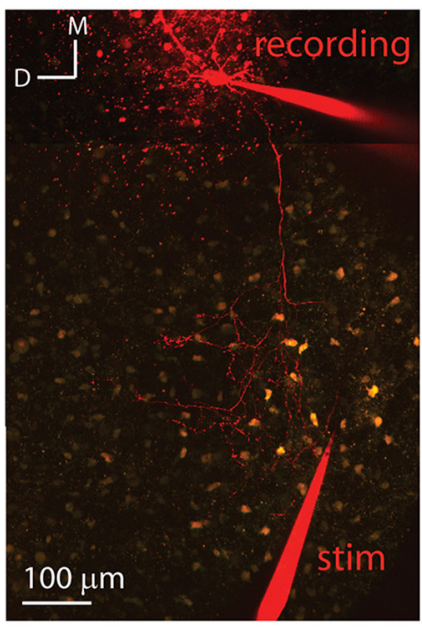

B

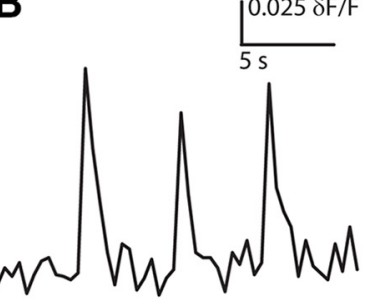

Somatic fluorescence response ROI 1

$\overline{\text { Axon terminal electrical stimulation }}$

\section{D}

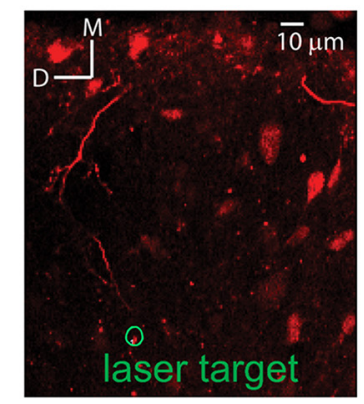

E

Control - no RuBi-GABA
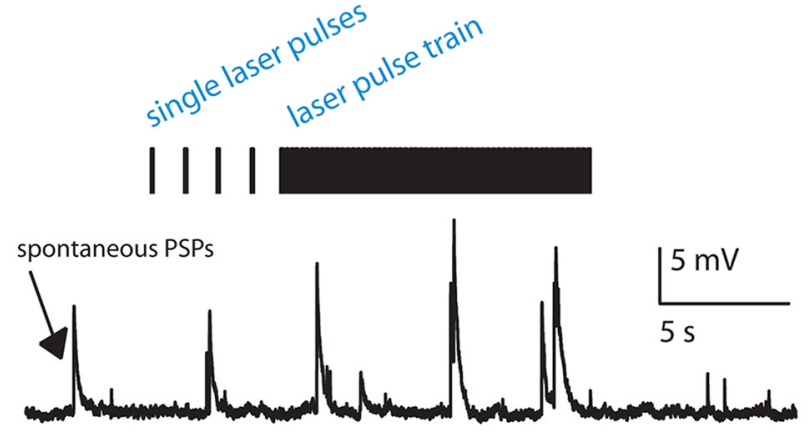

+ RuBi-GABA $(100 \mu \mathrm{M})$

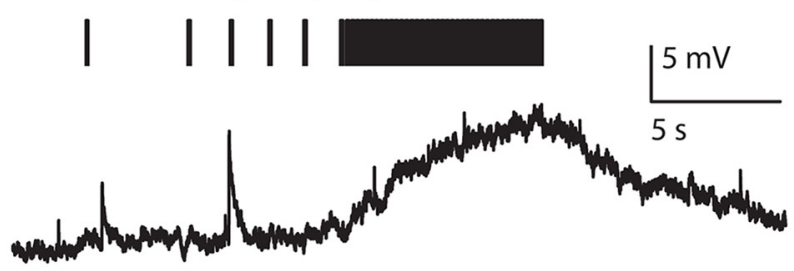

Figure 8. Focal uncaging of RuBi-GABA at MNTB axon terminals evokes a depolarization in the MNTB soma. $A, B$, Method to record from MNTB neuron with intact axon terminals in the LSO. Ai, MNTB neurons stained with the calcium indicator OGB-1 AM (green). Box represents region enlarged in Aii. Aii, Zoom of labeled MNTB neurons during baseline conditions. Aiii, Same view as Aii during electrical stimulation of MNTB axon terminals. Red box represents region of interest used to measure fluorescence intensity changes. $B, 0 G B-1$ AM response $(\delta F / F)$ for cell indicated in Aiii during electrical stimulation of MNTB axon terminals. $C$, Maximum intensity projection of a stack of 2-photon optical sections illustrating an MNTB neuron from
$1.67 \mathrm{~Hz}, n=5$ cells, $p=0.58)$. Although the lack of PPR change came unexpectedly, based upon these results, we conclude that $\mathrm{GABA}_{\mathrm{A}} \mathrm{R}$ activation on MNTB axon terminals does not alter vesicle release probability.

Action potentials evoked in MNTB neurons by axon terminal $\mathrm{GABA}_{\mathrm{A}} \mathrm{R}$ activation

We next tested whether presynaptic $\mathrm{GABA}_{\mathrm{A}}$ Rs could cause depolarization and action potentials in MNTB neurons by directly activating MNTB axon terminals via focal GABA application. MNTB neurons with uncut axons projecting to the LSO were first identified using a combination of electrical stimulation and 2-photon calcium imaging (Fig. 8A). To this end, we electrically stimulated the medial LSO ( 3 pulses at $100 \mathrm{~Hz}, 500 \mu \mathrm{A}$ ) while monitoring calcium responses elicited by antidromic spikes in OGB-1 labeled MNTB neurons (Fig. 8B). We then targeted responding MNTB neurons for whole-cell recordings using $100 \mu \mathrm{M}$ AlexaFluor-594 hydrazide containing pipettes to fill their axons (Fig. 8C). Following complete fill of the axonal arbor (45 $\mathrm{min}$ ), 20-100 $\mu \mathrm{M}$ RuBi-GABA, a caged GABA molecule (Rial Verde et al., 2008), was bath applied to the tissue. Single-pixel regions around Alexa-594 labeled axon branches in the medial LSO were targeted for RuBi-GABA uncaging using a $488 \mathrm{~nm}$ laser (Fig. 8D) while measuring somatic responses. Responses were not detected with single $100 \mathrm{~ms}$ laser pulses, but longer pulses $(500 \mathrm{~ms})$ or trains of shorter pulses at axons (100 ms pulse duration, $5 \mathrm{~Hz}$, train duration 8-26 s) elicited a slow depolarization or inward current in MNTB somata. With single $500 \mathrm{~ms}$ pulses, somatic responses were observed in 3 of 7 cells $(3.0 \pm 1.2 \mathrm{mV}, n=10$ stimulations, 2 cells; $-60.7 \pm 8.9$ pA, 6 stimulations, 1 cell). The average latency from the onset of laser illumination to the onset of response was $127.9 \pm 30.0 \mathrm{~ms}(n=16$ responses in 3 cells $)$. No responses were observed if the laser was targeted $200-300 \mu \mathrm{m}$ off the axons. Trains of laser pulses were more effective in eliciting somatic responses, generating long-lasting depolarizations in all MNTB neurons. This depolarization slowly increased throughout the train (peak depolarization $8.7 \pm 3.5 \mathrm{mV}$, train onset to response onset $568.4 \pm 485.6 \mathrm{~ms}$, latency to response plateau $9.4 \pm 1.8 \mathrm{~s}, n=13$ trains in 6 cells; Fig. $8 E$, bottom). The longer latencies observed with long train (8-26s) of shorter pulses compared with single $500 \mathrm{~ms}$ illumination may be due to a slower buildup of free, uncaged GABA perhaps exacerbated by diffusion and/or GABA reuptake (Stephan and Friauf, 2014). Laser light in the absence of RuBi-GABA did not elicit a response ( $n=5$ cells; Fig. $8 E$, top).

The RuBi-GABA evoked somatic depolarization indicates long distance communication in MNTB axons, suggesting a long passive length constant. The failure of RuBi-GABA uncaging to elicit antidromic action potentials in the MNTB was unexpected because the amplitudes of the second components in doublets suggest action potential driven activation of multiple release sites

\footnotetext{
$\leftarrow$

which recordings were performed (tiled). Neuron is filled with $100 \mu \mathrm{m}$ AlexaFluor-594 hydrazide via the recording electrode ("recording"). Electrical pulses were delivered via a glass pipette containing aCSF and $10 \mu$ m AlexaFluor-594 hydrazide in the LSO ("stim").D, Zoom of filled axon arbors in the LSO from a different cell as in $\boldsymbol{A}$ (single frame). Green circle represents region targeted for laser stimulation with a $488 \mathrm{~nm}$ laser; laser focuses on a pixel at the center of the circle. $\boldsymbol{E}$, Top, Voltage traces from an MNTB somata in control (no RuBi-GABA) conditions. Vertical lines indicate timing of single stimulating laser pulses, or laser pulse trains (pulse duration $100 \mathrm{~ms}$ ). Spontaneous postsynaptic potentials visible, indicated. Bottom, Same cell as top, with addition of RuBi-GABA to the bath solution (increased baseline noise due to the presence of RuBi-GABA).
} 
A

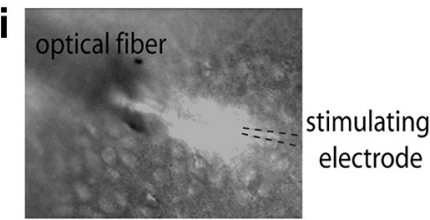

ii

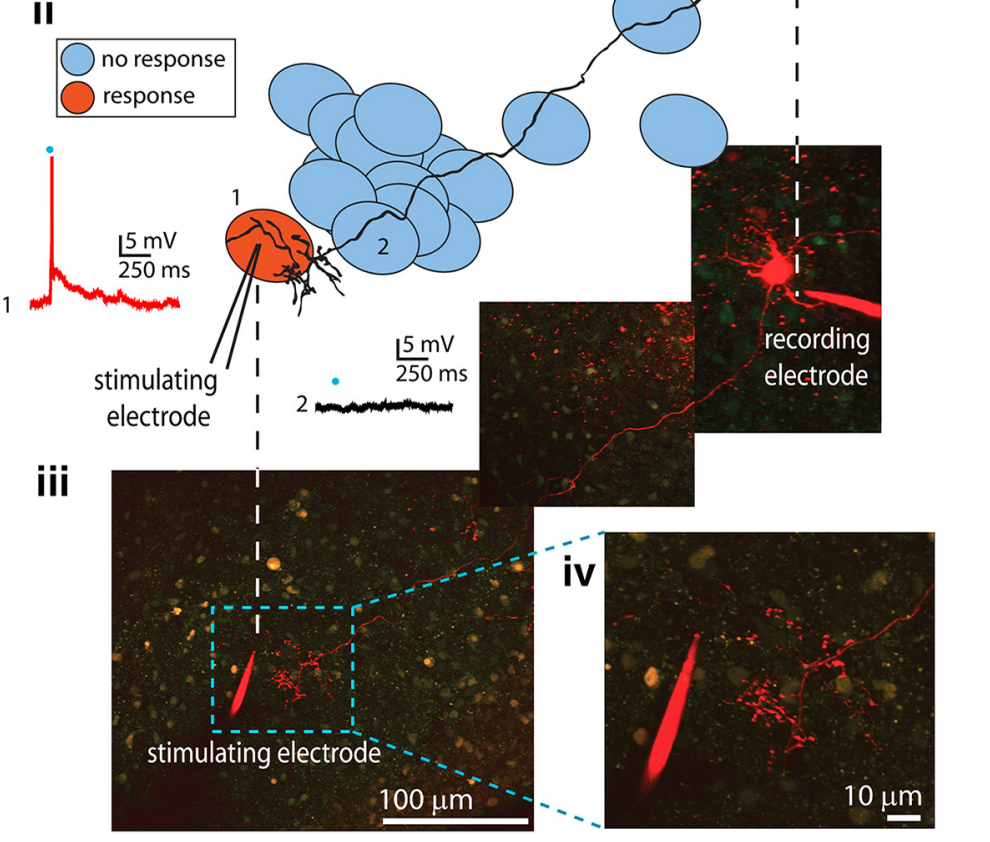

B
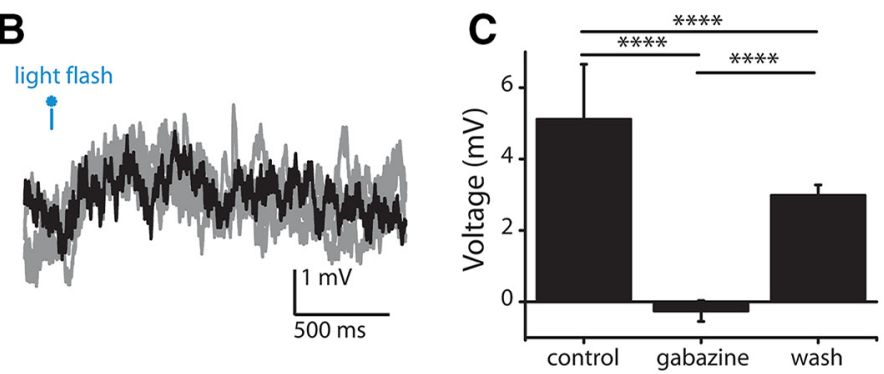

D

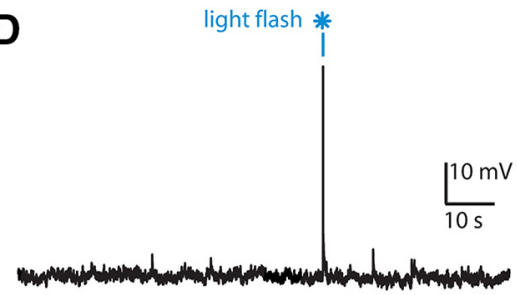

$\mathbf{F}$

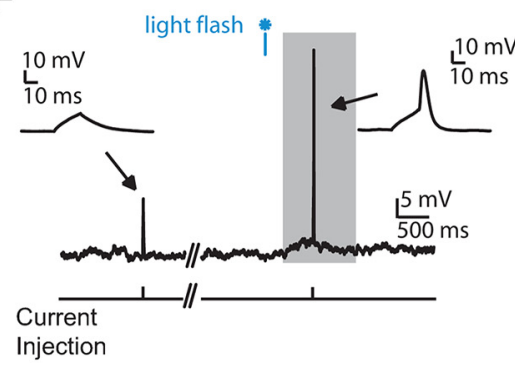

$100 u \mathrm{~m}$

recording electrod
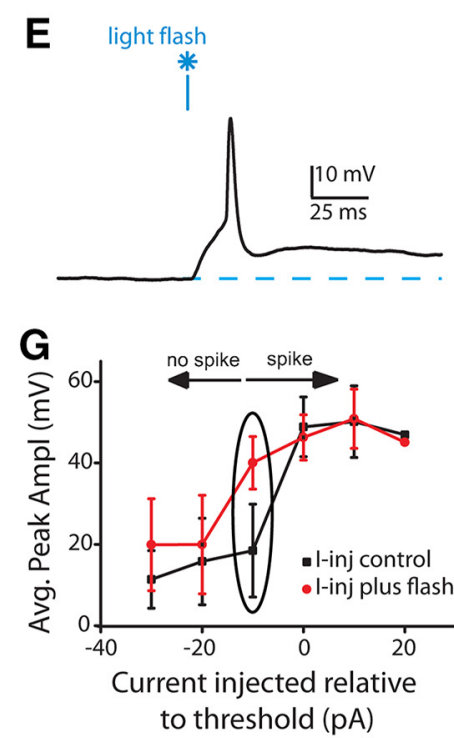

Figure 9. Photolytic uncaging of pHP-GABA at MNTB axon terminals via an optical fiber excites the MNTB soma. Ai, Bright-field image of a 50- $\mu \mathrm{m}$-diameter optical fiber illuminating a region of the $L S O$, electrical stimulating electrode approaching from the right. Aii, Diagram indicating reconstructed positions of illuminated areas (ovals), relative to MNTB axon position (same neuron as

(Kim and Kandler, 2010). Potential confounding factors that may explain the inability of RuBi-GABA uncaging to elicit antidromic spikes include GABA concentration (limited to $100 \mu \mathrm{M}$ RuBi-GABA) or uncaging volume, if spillover excitation requires interactions between MNTB neurons at multiple axon terminals. To overcome these limitations and increase GABA concentrations and volume, we used pHP-GABA, which, due to its higher stability, allowed higher concentrations

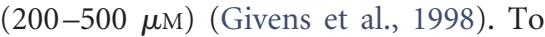
increase uncaging volume, we used illumination from a mercury lamp delivered by a 50 or $200 \mu \mathrm{m}$ optical fiber (Fig. 9A) (Kim and Kandler, 2003; Kandler et al., 2013). Under these conditions, single UV light pulses (100-500 ms) delivered to the MNTB axon terminals in the LSO reliably elicited somatic depolarizations in $40 \%$ of neurons $(4.9 \pm 2.7 \mathrm{mV} ; n=286$ trials, 11 cells; Fig. 9B). The average latency from flash onset to response onset was $172.2 \pm$ $152.6 \mathrm{~ms}(n=166$ responses in 5 cells

\section{$\leftarrow$}

in Aiii). Red oval (position 1) represents uncaging location that elicited a somatic response. Trace of corresponding somatic response shown to the left. Blue dot indicates timing of uncaging flash. Uncaging at nearby sections of axon did not evoke somatic responses (blue circles). Trace 2 indicates somatic voltage trace while uncaging at position 2 . Blue dot indicates timing of uncaging flash. Aiii, 3D projection, tiled, of filled MNTB neuron, same scale and aligned with Aii. Recording and stimulating electrodes contained AlexaFluor-594 hydrazide. Aiv, Zoom of region indicated in Aiii. B, Overlay of 5 sequential current-clamp traces at $20 \mathrm{~s}$ intervals showing somatic response to focal fiber uncaging of $200 \mu \mathrm{m} \mathrm{PHP-GABA}$ in the LSO. Representative response shown in black. Light flash from optical fiber begins at the time indicated by the blue vertical line. C, Summary of peak somatic voltage changes induced by pHPGABA uncaging at MNTB axon terminals in control conditions (200 $\mu \mathrm{m}$ pHP-GABA), with $30 \mu \mathrm{m}$ gabazine, and after wash of gabazine. $D$, Example of action potential recorded from MNTB somata by pHP-GABA uncaging at MNTB axon terminals in the LSO. $\boldsymbol{E}$, Zoom of action potential from $\boldsymbol{D}$. $\boldsymbol{F}$, Example trace showing the voltage responses of an MNTB neuron to somatic current injection ( $60 \mathrm{pA}, 10 \mathrm{~ms})$. Left, Without light flash, the current injection evokes a subthreshold depolarization. Inset, Zoom of subthreshold current. Right, Light flash begins at the vertical blue line, approximate period of slow somatic depolarization indicated by shaded box. Identical current injection ( 60 pA, $10 \mathrm{~ms})$, timed to coincide with the peak of the depolarizing response, evokes an action potential. Inset, Zoom of action potential waveform. G, Plot of the amplitude of the voltage response evoked in MNTB somata by current injection through the recording pipette (duration $10 \mathrm{~ms}$ ) of varying amplitudes. I-injection ( $x$-axis) is relative to the amount of current that evoked action potentials in control conditions (set to $0 \mathrm{pA}$ ). Black represents amplitude of voltage traces for I-injection in control conditions (no light flash). Red represents amplitude of voltage traces during pHP-GABA uncaging (with light flash) at MNTB axon terminals. Oval represents the current injection amplitude at which action potentials are evoked in light flash conditions, but not in control conditions. 
using $50 \mu \mathrm{m}$ fibers). This latency is still considerably longer than expected based on the latencies between double components. Whereas limitations in buildup of free GABA, similar to those described for the RuBi-GABA experiments, apply for the pHPGABA as well, the longer latencies of somatic depolarization observed with uncaging may indicate that doublets are the result of local spiking with the local axon arbors that fail to backpropagate to the MNTB soma.

Responses elicited by uncaging pHP GABA were blocked by $30 \mu \mathrm{M}$ gabazine, indicating that $\mathrm{GABA}_{\mathrm{A}} \mathrm{R}$ activation is necessary for GABA uncaging elicited somatic depolarizations (Fig. 9C). Fiber positions were selected using bright-field optics and a CCD camera, so experiments were blind as to the axon arbor location. Post hoc localization of axon arbors confirmed that uncaging regions that successfully elicited somatic responses indeed contained MNTB axon terminals (Fig. 9Aiii,iv) and were spatially restricted (average region that evoked a response: $45.2 \pm 20.6$ $\mu \mathrm{m}, n=6$ cells). Uncaging along the axon did not elicit responses (Fig. 9A).

$\mathrm{GABA}_{\mathrm{A}} \mathrm{R}$ activation by axonal pHP-GABA uncaging could also trigger an action potential ( 3 of 11 neurons; latency from flash onset to spike $423.5 \pm 454.5 \mathrm{~ms}, n=3$ neurons; not different from latency from flash onset to response onset in no-spike trials, $p=0.28$; Fig. $9 E, F)$. We attribute the larger variability and longer average latencies of somatic depolarizations elicited by axonal GABA uncaging compared with the latencies between the doublet components, to a slow buildup of free GABA at responsive axon terminals due to poor UV light penetration into the slice combined with a variable depth of the axon in the slice. Consistent with this explanation, the shortest latency of spike responses was observed in an axon with terminals at the slice surface.

Finally, we examined whether subthreshold depolarization can increase excitability of MNTB neurons by bringing the membrane potential closer to spike threshold. To test this, we paired pHP-GABA uncaging at MNTB axon terminals with somatic current injections. Axon-elicited somatic depolarizations lowered the amplitude of current injection necessary to evoke an action potential in 5 of 6 cells (excitability index of $0.69 \pm 0.51$, $n=18$ pairs of control and GABA stimuli, 6 cells; Fig. $9 F, G$ ). Therefore, focal GABA application to MNTB axon terminals by uncaging could directly evoke a spike that was measured at the soma, and could also increase the excitability of the soma in response to subthreshold stimuli.

\section{Discussion}

Here we provide evidence that GABA released from MNTB axon terminals in the LSO can spill over to neighboring terminals activating $\mathrm{GABA}_{\mathrm{A}}$ receptors. At MNTB axon terminals, GABA is excitatory, causing neurotransmitter release. GABA depolarization elicited in the terminal propagated back to the MNTB cell bodies, increasing their excitability. Interaxonal GABA spillover provides a novel mode of communication between neighboring, likely tonotopically related, MNTB neurons.

\section{Mechanism of interaxonal communication between MNTB neurons}

We propose that excitatory GABA spillover between MNTB axon terminals can generate doublet PSCs in LSO neurons. According to this scenario, the first component of the doublet PSC is due to direct electrical stimulation-evoked neurotransmitter release from MNTB axons. The second component is due to GABA spillover between different MNTB axons in the LSO, causing excita- tion via activation of axon terminal $\mathrm{GABA}_{\mathrm{A}} \mathrm{R}$, and additional neurotransmitter release at a slight $(\sim 3 \mathrm{~ms})$ delay. Doublets are a robust occurrence in the slice preparation, observed in $>50 \%$ of cells in animals aged P3-P21. Although postsynaptic $\mathrm{GABA}_{\mathrm{A}} \mathrm{R}-$ mediated responses are reduced with development (Kotak et al., 1998; Kullmann et al., 2002; Nabekura et al., 2004; Kim and Kandler, 2010), MNTB neurons continue to show immunohistochemical evidence for GABA production into adulthood (Dupont et al., 1990; Henkel and Brunso-Bechtold, 1998; Korada and Schwartz, 1999). Our results argue against potential alternative explanations for the doublet PSCs. First, multicomponent PSCs could arise from repeated spiking of an MNTB axon. However, in our preparation, MNTB axons could not release neurotransmitter at the rate of $\sim 300 \mathrm{~Hz}$ that would be necessary to account for the $\sim 3 \mathrm{~ms}$ interval between doublet components (Fig. 2A). Second, doublet PSC may be caused by activation of a disynaptic pathway. However, this would require GABAergic excitation of an intermediate cell, which is unlikely to occur after P10 because doublets still occur when GABA has become hyperpolarizing in the SOC (Kandler and Friauf, 1995; Kullmann and Kandler, 2001; Löhrke et al., 2005). Third, electrical coupling by gap junctions of MNTB axons could mediate interaxonal communication. This also is unlikely as the $\sim 3 \mathrm{~ms}$ latency between doublet components is too slow for this scenario (Schmitz et al., 2001b; Apostolides and Trussell, 2013). Fourth, the doublets may result from activation of MNTB axons with different conduction velocities or speeds of release. However, in this scenario, we would not expect an abrupt loss of the second doublet component at high stimulus intensities that we observed. Fifth, the two components of the doublet PSCs may be mediated by different neurotransmitters at different synapses such that receptor antagonists simply inhibit one set of synapses. However, this would predict that the second component would be reduced gradually with antagonist wash-in, contrary to the stochastic "blinking" of the second doublet component that we observed.

Excitatory GABA spillover depends on a high intracellular chloride concentration in MNTB axon terminals. In the developing SOC, $\mathrm{GABA}_{\mathrm{A}}$ and glycine receptor currents measured at the soma switch from depolarizing to hyperpolarizing early in development as intracellular chloride concentrations decrease (Kandler and Friauf, 1995; Ehrlich et al., 1999; Kullmann and Kandler, 2001; Löhrke et al., 2005). The fact that GABA-mediated doublets persist at least through the third postnatal week indicates that MNTB axon terminals maintain a high chloride concentration, consistent with what has been shown in terminals from other neurons (Zhang and Jackson, 1995; Price and Trussell, 2006; Dellal et al., 2012).

GABA spillover excitation at MNTB axon terminals highlights the important role of GABA reuptake in this auditory circuit (Stephan and Friauf, 2014). Although the presence or developmental regulation of neurotransmitter transporters in the SOC is still poorly understood, our results predict that regulation of reuptake mechanisms in the LSO are important to regulate maturation and synaptic processing in the MNTB-LSO pathway.

\section{Mechanism of MNTB excitation by interaxonal GABA spillover excitation}

Work presented here describes a novel mechanism of communication between MNTB neurons by demonstrating interaxonal excitatory GABA spillover. Through this mechanism, MNTB axon terminals can recruit other nearby terminals and signal in noncanonical directions, from the axon terminal back to the soma. Interaxonal GABA spillover between MNTB neurons may 
augment signaling in three general ways, including increasing neurotransmitter release locally at axon terminals, generating subthreshold depolarization of the soma, and directly evoking somatic spikes. First, axon terminal depolarization via GABA spillover may affect neurotransmitter release by altering action potential propagation or the likelihood that an action potential will trigger vesicle fusion, as has been shown in other systems (Schmitz et al., 2001a; Ruiz et al., 2003, 2010; Alle and Geiger, 2006, 2007; Shu et al., 2006; Kole et al., 2007; Christie and Jahr, 2008), including the auditory system (Turecek and Trussell, 2001; Paradiso and Wu, 2009). However, our results investigating PPRs and spontaneous PSC rates suggest that GABA spillover is not affecting the probability of neurotransmitter release in this manner. Second, passive subthreshold depolarization of the MNTB soma initiated by axon terminal $\mathrm{GABA}_{\mathrm{A}} \mathrm{R}$ activation may enhance the excitability of the neuron in response to additional signals, such as synaptic inputs. This mechanism is supported by our experiments pairing subthreshold GABA-evoked depolarization with an additional subthreshold signal to generate somatic spikes. Finally, our results also support the ability of GABA spillover-evoked depolarization at axon terminals to directly excite the soma (Trigo et al., 2010) and generate somatic action potentials, as has been shown in cerebellum (Pugh and Jahr, 2013), which can initiate signaling independent of additional afferent activity.

MNTB neurons receive one single, large and secure excitatory synapse, the calyx of Held, formed by axons from globular bushy cells (Morest, 1968; Smith et al., 1991; Kandler and Friauf, 1993; Schneggenburger and Forsythe, 2006; Hoffpauir et al., 2010; Holcomb et al., 2013). Because of this characteristic 1:1 innervation, the highly secure synaptic transmission, and the absence of local MNTB collaterals (Banks and Smith, 1992; Sommer et al., 1993; Smith et al., 1998), MNTB neurons are generally regarded as parallel relays. Excitatory GABA spillover between MNTB axons modifies this view by providing a means through which MNTB neurons can communicate with each other.

\section{Possible function of interaxonal GABA spillover in the MNTB-LSO pathway}

Projections from the MNTB to the LSO undergo functional and structural refinement during development. Before hearing onset, MNTB synapses onto LSO neurons are either silenced or strengthened. After hearing onset, this is followed by pruning of MNTB axon collaterals, resulting in a tonotopically more precise circuit (Sanes, 1993; Kim and Kandler, 2003; Hirtz et al., 2012; Clause et al., 2014). GABA spillover excitation may be a mechanism that participates in this functional refinement by coordinating neurotransmitter release from neurons with similar tonotopic locations. Simultaneous activation of MNTB neurons with a high degree of axon terminal overlap in the LSO would favor GABA spillover and the recruitment of axon terminals arising from tonotopically similar but not concurrently active MNTB neurons, selectively enhancing these connections. Conversely, axon terminals from different tonotopic regions that have little or no axon terminal overlap would be unlikely to entrain one another, resulting in a weakening and loss of these connections. Interestingly, GABA spillover by repeated axon stimulation is most pronounced at $50 \mathrm{~Hz}$, which is a spike frequency that rarely occurs in spontaneous activity before hearing onset (Tritsch et al., 2010; Clause et al., 2014). Because there is a paucity of $50 \mathrm{~Hz}$ firing in vivo, the entrainment of low-density boutons from tonotopically distant MNTB neurons would be minimal. Intriguingly, spontaneous firing rates $\sim 50 \mathrm{~Hz}$ are prominent in mice which lack the $\alpha 9$ acetylcholine receptor subunit in cochlear hair cells, and likewise show an impairment in the tonotopic refinement of the MNTB-LSO pathway (Clause et al., 2014).

After hearing onset ( $\sim \mathrm{P} 12$ in rodents), MNTB neurons in vivo fire at $\sim 10-60 \mathrm{~Hz}$ spontaneously and have sound evoked firing rates upward of $100 \mathrm{~Hz}$ (Spirou et al., 1990; Sommer et al., 1993; Smith et al., 1998; Kopp-Scheinpflug et al., 2003; Kadner et al., 2006; Hermann et al., 2007; Tolnai et al., 2008). Therefore, the neurotransmitter spillover excitation mechanism may be fully engaged in vivo without sound stimulation. As MNTB neurons are primarily glycinergic after hearing onset, spillover at this age may be mediated primarily by glycine. MNTB neurons with a high degree of axon arbor overlap, specifically neurons from the same tonotopic location in the MNTB, may tonically depolarize each other, perhaps contributing to the reliable postsynaptic spiking.

\section{References}

Alamilla J, Gillespie DC (2013) Maturation of calcium-dependent GABA, glycine, and glutamate release in the glycinergic MNTB-LSO pathway. PLoS One 8:e75688. CrossRef Medline

Alle H, Geiger JR (2006) Combined analog and action potential coding in hippocampal mossy fibers. Science 311:1290-1293. CrossRef Medline

Alle H, Geiger JR (2007) GABAergic spill-over transmission onto hippocampal mossy fiber boutons. J Neurosci 27:942-950. CrossRef Medline

Apostolides PF, Trussell LO (2013) Rapid, activity-independent turnover of vesicular transmitter content at a mixed glycine/GABA synapse. J Neurosci 33:4768-4781. CrossRef Medline

Awatramani GB, Price GD, Trussell LO (2005) Modulation of transmitter release by presynaptic resting potential and background calcium levels. Neuron 48:109-121. CrossRef Medline

Banks MI, Smith PH (1992) Intracellular recordings from neurobiotinlabeled cells in brain slices of the rat medial nucleus of the trapezoid body. J Neurosci 12:2819-2837. Medline

Boudreau JC, Tsuchitani C (1970) Cat superior olive S-segment cell discharge to tonal stimulation. Contrib Sens Physiol 4:143-213. CrossRef Medline

Caird D, Klinke R (1983) Processing of binaural stimuli by cat superior olivary complex neurons. Exp Brain Res 52:385-399. Medline

Chang EH, Kotak VC, Sanes DH (2003) Long-term depression of synaptic inhibition is expressed postsynaptically in the developing auditory system. J Neurophysiol 90:1479-1488. CrossRef Medline

Christie JM, Jahr CE (2008) Dendritic NMDA receptors activate axonal calcium channels. Neuron 60:298-307. CrossRef Medline

Clause A, Kim G, Sonntag M, Weisz CJ, Vetter DE, Rubsamen R, Kandler K, Rûsamen R, Kandler K (2014) The precise temporal pattern of prehearing spontaneous activity is necessary for tonotopic map refinement. Neuron 82:822-835. CrossRef Medline

de Blas AL, Vitorica J, Friedrich P (1988) Localization of the GABAA receptor in the rat brain with a monoclonal antibody to the $57,000 \mathrm{Mr}$ peptide of the GABAA receptor/benzodiazepine receptor/Cl- channel complex. J Neurosci 8:602-614. Medline

Dellal SS, Luo R, Otis TS (2012) GABAA receptors increase excitability and conduction velocity of cerebellar parallel fiber axons. J Neurophysiol 107: 2958-2970. CrossRef Medline

Dupont J, Geffard M, Calas A, Aran JM (1990) Immunohistochemical evidence for GABAergic cell bodies in the medial nucleus of the trapezoid body and in the lateral vestibular nucleus in the guinea pig brainstem. Neurosci Lett 111:263-268. CrossRef Medline

Eccles JC, Schmidt R, Willis WD (1963) Pharmacological studies on presynaptic inhibition. J Physiol 168:500-530. CrossRef Medline

Ehrlich I, Lohrke S, Friauf E (1999) Shift from depolarizing to hyperpolarizing glycine action in rat auditory neurones is due to age-dependent $\mathrm{Cl}^{-}$ regulation. J Physiol 520:121-137. CrossRef Medline

Finlayson PG, Caspary DM (1989) Synaptic potentials of chinchilla lateral superior olivary neurons. Hear Res 38:221-228. CrossRef Medline

Gillespie DC, Kim G, Kandler K (2005) Inhibitory synapses in the developing auditory system are glutamatergic. Nat Neurosci 8:332-338. CrossRef Medline

Givens RS, Jung AH, Park CH, Weber JFW, Bartlett W (1997) New photoactivated protecting groups. 7. p-Hydroxyphenacyl: a phototrigger for 
excitatory amino acids and peptides. J Am Chem Soc 119:8379-8370. CrossRef

Givens RS, Weber JF, Jung AH, Park CH (1998) New photoprotecting groups: desyl and $p$-hydroxyphenacyl phosphate and carboxylate esters. Methods Enzymol 291:1-29. CrossRef Medline

Glickfeld LL, Roberts JD, Somogyi P, Scanziani M (2009) Interneurons hyperpolarize pyramidal cells along their entire somatodendritic axis. Nat Neurosci 12:21-23. CrossRef Medline

Grothe B, Koch U (2011) Dynamics of binaural processing in the mammalian sound localization pathway: the role of GABA(B) receptors. Hear Res 279:43-50. CrossRef Medline

Henkel CK, Brunso-Bechtold JK (1998) Calcium-binding proteins and GABA reveal spatial segregation of cell types within the developing lateral superior olivary nucleus of the ferret. Microsc Res Tech 41:234-245. CrossRef Medline

Hermann J, Pecka M, von Gersdorff H, Grothe B, Klug A (2007) Synaptic transmission at the calyx of Held under in vivo like activity levels. J Neurophysiol 98:807-820. CrossRef Medline

Hirtz JJ, Braun N, Griesemer D, Hannes C, Janz K, Löhrke S, Müller B, Friauf E (2012) Synaptic refinement of an inhibitory topographic map in the auditory brainstem requires functional CaV1.3 calcium channels. J Neurosci 32:14602-14616. CrossRef Medline

Hnasko TS, Edwards RH (2012) Neurotransmitter corelease: mechanism and physiological role. Annu Rev Physiol 74:225-243. CrossRef Medline

Hoffpauir BK, Kolson DR, Mathers PH, Spirou GA (2010) Maturation of synaptic partners: functional phenotype and synaptic organization tuned in synchrony. J Physiol 588:4365-4385. CrossRef Medline

Holcomb PS, Hoffpauir BK, Hoyson MC, Jackson DR, Deerinck TJ, Marrs GS, Dehoff M, Wu J, Ellisman MH, Spirou GA (2013) Synaptic inputs compete during rapid formation of the calyx of Held: a new model system for neural development. J Neurosci 33:12954-12969. CrossRef Medline

Jang IS, Nakamura M, Ito Y, Akaike N (2006) Presynaptic GABAA receptors facilitate spontaneous glutamate release from presynaptic terminals on mechanically dissociated rat CA3 pyramidal neurons. Neuroscience 138: 25-35. CrossRef Medline

Kadner A, Kulesza RJ Jr, Berrebi AS (2006) Neurons in the medial nucleus of the trapezoid body and superior paraolivary nucleus of the rat may play a role in sound duration coding. J Neurophysiol 95:1499-1508. CrossRef Medline

Kandler K, FriaufE (1993) Pre- and post-natal development of efferent connections of the cochlear nucleus in the rat. J Comp Neurol 328:161-184. CrossRef Medline

Kandler K, Friauf E (1995) Development of glycinergic and glutamatergic synaptic transmission in the auditory brainstem of perinatal rats. J Neurosci 15:6890-6904. Medline

Kandler K, Nguyen T, Noh J, Givens RS (2013) An optical fiber-based uncaging system. Cold Spring Harb Protoc 2013:118-121. CrossRef Medline

Kim G, Kandler K (2003) Elimination and strengthening of glycinergic/ GABAergic connections during tonotopic map formation. Nat Neurosci 6:282-290. CrossRef Medline

Kim G, Kandler K (2010) Synaptic changes underlying the strengthening of $\mathrm{GABA} /$ glycinergic connections in the developing lateral superior olive. Neuroscience 171:924-933. CrossRef Medline

Kole MH, Letzkus JJ, Stuart GJ (2007) Axon initial segment Kvl channels control axonal action potential waveform and synaptic efficacy. Neuron 55:633-647. CrossRef Medline

Kopp-Scheinpflug C, Lippe WR, Dörrscheidt GJ, Rübsamen R (2003) The medial nucleus of the trapezoid body in the gerbil is more than a relay: comparison of pre- and post-synaptic activity. J Assoc Res Otolaryngol 4:1-23. CrossRef Medline

Korada S, Schwartz IR (1999) Development of GABA, glycine, and their receptors in the auditory brainstem of gerbil: a light and electron microscopic study. J Comp Neurol 409:664-681. CrossRef Medline

Kotak VC, Korada S, Schwartz IR, Sanes DH (1998) A developmental shift from GABAergic to glycinergic transmission in the central auditory system. J Neurosci 18:4646-4655. Medline

Kotak VC, DiMattina C, Sanes DH (2001) GABA(B) and Trk receptor signaling mediates long-lasting inhibitory synaptic depression. J Neurophysiol 86:536-540. Medline

Kullmann PH, Kandler K (2001) Glycinergic/GABAergic synapses in the lateral superior olive are excitatory in neonatal C57BL/6J mice. Brain Res Dev Brain Res 131:143-147. CrossRef Medline

Kullmann PH, Ene FA, Kandler K (2002) Glycinergic and GABAergic calcium responses in the developing lateral superior olive. Eur J Neurosci 15:1093-1104. CrossRef Medline

Löhrke S, Srinivasan G, Oberhofer M, Doncheva E, Friauf E (2005) Shift from depolarizing to hyperpolarizing glycine action occurs at different perinatal ages in superior olivary complex nuclei. Eur J Neurosci 22: 2708-2722. CrossRef Medline

Magnusson AK, Park TJ, Pecka M, Grothe B, Koch U (2008) Retrograde GABA signaling adjusts sound localization by balancing excitation and inhibition in the brainstem. Neuron 59:125-137. CrossRef Medline

Morest DK (1968) The collateral system of the medial nucleus of the trapezoid body of the cat, its neuronal architecture and relation to the olivocochlear bundle. Brain Res 9:288-311. CrossRef Medline

Nabekura J, Katsurabayashi S, Kakazu Y, Shibata S, Matsubara A, Jinno S, Mizoguchi Y, Sasaki A, Ishibashi H (2004) Developmental switch from GABA to glycine release in single central synaptic terminals. Nat Neurosci 7:17-23. CrossRef Medline

Noh J, Seal RP, Garver JA, Edwards RH, Kandler K (2010) Glutamate corelease at GABA/glycinergic synapses is crucial for the refinement of an inhibitory map. Nat Neurosci 13:232-238. CrossRef Medline

Oertel D (1999) The role of timing in the brain stem auditory nuclei of vertebrates. Annu Rev Physiol 61:497-519. CrossRef Medline

Paradiso K, Wu LG (2009) Small voltage changes at nerve terminals travel up axons to affect action potential initiation. Nat Neurosci 12:541-543. CrossRef Medline

Price GD, Trussell LO (2006) Estimate of the chloride concentration in a central glutamatergic terminal: a gramicidin perforated-patch study on the calyx of Held. J Neurosci 26:11432-11436. CrossRef Medline

Pugh JR, Jahr CE (2011) Axonal GABAA receptors increase cerebellar granule cell excitability and synaptic activity. J Neurosci 31:565-574. CrossRef Medline

Pugh JR, Jahr CE (2013) Activation of axonal receptors by GABA spillover increases somatic firing. J Neurosci 33:16924-16929. CrossRef Medline

Rial Verde EM, Zayat L, Etchenique R, Yuste R (2008) Photorelease of GABA with visible light using an inorganic caging group. Front Neural Circuits 2:2. CrossRef Medline

Rietzel HJ, FriaufE (1998) Neuron types in the rat lateral superior olive and developmental changes in the complexity of their dendritic arbors. J Comp Neurol 390:20-40. CrossRef Medline

Rubio ME, Wenthold RJ (1997) Glutamate receptors are selectively targeted to postsynaptic sites in neurons. Neuron 18:939-950. CrossRef Medline

Ruiz A, Fabian-Fine R, Scott R, Walker MC, Rusakov DA, Kullmann DM (2003) GABAA receptors at hippocampal mossy fibers. Neuron 39:961973. CrossRef Medline

Ruiz A, Campanac E, Scott RS, Rusakov DA, Kullmann DM (2010) Presynaptic GABAA receptors enhance transmission and LTP induction at hippocampal mossy fiber synapses. Nat Neurosci 13:431-438. CrossRef Medline

Sanes DH (1993) The development of synaptic function and integration in the central auditory system. J Neurosci 13:2627-2637. Medline

Schmitz D, Mellor J, Nicoll RA (2001a) Presynaptic kainate receptor mediation of frequency facilitation at hippocampal mossy fiber synapses. Science 291:1972-1976. CrossRef Medline

Schmitz D, Schuchmann S, Fisahn A, Draguhn A, Buhl EH, Petrasch-Parwez E, Dermietzel R, Heinemann U, Traub RD, Berlin H (2001b) Axoaxonal coupling: a novel mechanism for ultrafast neuronal communication. Neuron 31:831-840. CrossRef Medline

Schneggenburger R, Forsythe ID (2006) The calyx of Held. Cell Tissue Res 326:311-337. CrossRef Medline

Shu Y, Hasenstaub A, Duque A, Yu Y, McCormick DA (2006) Modulation of intracortical synaptic potentials by presynaptic somatic membrane potential. Nature 441:761-765. CrossRef Medline

Smith PH, Joris PX, Carney LH, Yin TC (1991) Projections of physiologically characterized globular bushy cell axons from the cochlear nucleus of the cat. J Comp Neurol 304:387-407. CrossRef Medline

Smith PH, Joris PX, Yin TC (1998) Anatomy and physiology of principal cells of the medial nucleus of the trapezoid body (MNTB) of the cat. J Neurophysiol 79:3127-3142. Medline

Sommer I, Lingenhöhl K, Friauf E (1993) Principal cells of the rat medial 
nucleus of the trapezoid body: an intracellular in vivo study of their physiology and morphology. Exp Brain Res 95:223-239. Medline

Spirou GA, Brownell WE, Zidanic M (1990) Recordings from cat trapezoid body and HRP labeling of globular bushy cell axons. J Neurophysiol 63: 1169-1190. Medline

Stell BM (2011) Biphasic action of axonal GABA-A receptors on presynaptic calcium influx. J Neurophysiol 105:2931-2936. CrossRef Medline

Stell BM, Rostaing P, Triller A, Marty A (2007) Activation of presynaptic $\mathrm{GABA}(\mathrm{A})$ receptors induces glutamate release from parallel fiber synapses. J Neurosci 27:9022-9031. CrossRef Medline

Stephan J, Friauf E (2014) Functional analysis of the inhibitory neurotransmitter transporters GlyT1, GAT-1, and GAT-3 in astrocytes of the lateral superior olive. Glia 62:1992-2003. CrossRef Medline

Sterenborg JC, Pilati N, Sheridan CJ, Uchitel OD, Forsythe ID, Barnes-Davies M (2010) Lateral olivocochlear (LOC) neurons of the mouse LSO receive excitatory and inhibitory synaptic inputs with slower kinetics than LSO principal neurons. Hear Res 270:119-126. CrossRef Medline

Tollin DJ (2003) The lateral superior olive: a functional role in sound source localization. Neuroscientist 9:127-143. CrossRef Medline

Tolnai S, Hernandez O, Englitz B, Rübsamen R, Malmierca MS (2008) The medial nucleus of the trapezoid body in rat: spectral and temporal properties vary with anatomical location of the units. Eur J Neurosci 27:25872598. CrossRef Medline
Trattner B, Berner S, Grothe B, Kunz L (2013) Depolarization-induced suppression of a glycinergic synapse in the superior olivary complex by endocannabinoids. J Neurochem 127:78-90. CrossRef Medline

Trigo FF, Bouhours B, Rostaing P, Papageorgiou G, Corrie JE, Triller A, Ogden D, Marty A (2010) Presynaptic miniature gabaergic currents in developing interneurons. Neuron 66:235-247. CrossRef Medline

Tritsch NX, Rodríguez-Contreras A, Crins TT, Wang HC, Borst JG, Bergles DE (2010) Calcium action potentials in hair cells pattern auditory neuron activity before hearing onset. Nat Neurosci 13:1050-1052. CrossRef Medline

Turecek R, Trussell LO (2001) Presynaptic glycine receptors enhance transmitter release at a mammalian central synapse. Nature 411:587-590. CrossRef Medline

Turecek R, Trussell LO (2002) Reciprocal developmental regulation of presynaptic ionotropic receptors. Proc Natl Acad Sci U S A 99:13884-13889. CrossRef Medline

Vaaga CE, Borisovska M, Westbrook GL (2014) Dual-transmitter neurons: functional implications of corelease and transmission. Curr Opin Neurobiol 29C:25-32. CrossRef Medline

Zhang SJ, Jackson MB (1995) GABAA receptor activation and the excitability of nerve terminals in the rat posterior pituitary. J Physiol 483:583-595. CrossRef Medline 